Reporting sexual exploitation and abuse by UN peacekeeping personnel: A research proposal on community perspectives by

Kaila Mintz

BA (Hons) York University (Glendon College), 2004

\author{
A Major Research Paper \\ presented to Ryerson University
}

in partial fulfillment of the requirements for the degree of

\author{
Master of Arts \\ in the Program of \\ Immigration and Settlement Studies \\ Toronto, Ontario, Canada, 2016 \\ (C) Kaila Mintz 2016
}




\section{AUTHOR'S DECLARATION FOR ELECTRONIC SUBMISSION OF A MAJOR RESEARCH PAPER (MRP)}

I hereby declare that I am the sole author of this Major Research Paper. This is a true copy of the MRP, including any required final revisions, as accepted by my examiners.

I authorize Ryerson University to lend this MRP to other institutions or individuals for the purpose of scholarly research.

I further authorize Ryerson University to reproduce this MRP by photocopying or by other means, in total or in part, at the request of other institutions or individuals for the purpose of scholarly research. I understand that my MRP may be made electronically available to the public.

Kaila Mintz 


\title{
Reporting sexual exploitation and abuse by UN peacekeeping personnel: A research proposal on community perspectives
}

\author{
Kaila Mintz \\ Master of Arts 2016 \\ Immigration and Settlement Studies \\ Ryerson University
}

\begin{abstract}
Persons displaced by conflict are considered especially vulnerable to sexual abuse by peacekeepers. While the UN reports publicly on allegations of "sexual exploitation and abuse" by peacekeepers, it is widely acknowledged that under-reporting is a significant problem. Proposed qualitative research involving local civil society organizations and community leaders supporting victims in the context of displacement will elicit their perceptions on the barriers to, and challenges associated with, formal reporting. The planned study, set out as a proposal, will assess perceptions of current reporting structures and recent UN reforms regarding "community-based complaint reception mechanisms." This will inform further research and consultations into the design of more appropriate reporting structures. The research's dissemination, linked to the Code Blue campaign's advocacy to end impunity for sexual violence by peacekeepers, will seek to convince UN decisionmakers that systemic reforms are needed to ensure that victims have better access to appropriate support and criminal justice.
\end{abstract}

Keywords: internally displaced persons; refugees; sexual violence; sexual exploitation and abuse; under-reporting; peacekeeping; United Nations 


\section{ACKNOWLEDGEMENTS AND DEDICATION}

I would like to thank my MRP supervisor, Professor Myer Siemiatycki, for his significant encouragement, support and input. Professor Siemiatycki was an invaluable source of inspiration and connections for me during my time at Ryerson University, and his faith in me, coupled with his compassion and our shared passion for social justice, enabled me to persevere despite challenging personal circumstances. I am also grateful for the input and support from my second reader, Assistant Professor Miriam Anderson. I appreciated her insightful and thought-provoking comments, excellent further reading suggestions and encouragement to take this research forward. I would also like to thank the other professors and staff associated with the ISS program and my fellow students who have supported me along the way.

I am humbled by the passion, dedication, creativity and intellect of my colleagues at AIDS-Free World and our collaborators on the Code Blue campaign, and acknowledge that the paper's content and analysis has been shaped by their keen insights. In particular, I thank our co-Directors, Paula Donovan and Stephen Lewis, for their support, patience and encouragement as I completed this paper, and for their expert guidance in the landscape of feminist social justice advocacy. I am most grateful to Dr. Rosa Freedman for her thoughtful insights and suggestions, and for her unwavering enthusiasm for this project.

I thank my family and friends for the steadfast encouragement (and gentle nudging), and especially my parents, Diane and Eric, for providing such a supportive and caring environment for me to focus on completing my paper. My father Eric helped me think through the more challenging aspects of this project.

This paper is dedicated to my late brother Aaron, whose sharp intellect and passion for social justice through the law (and its reform) serves as an enduring inspiration. 


\section{TABLE OF CONTENTS}

AUTHOR'S DECLARATION FOR ELECTRONIC SUBMISSION OF A MAJOR RESEARCH PAPER

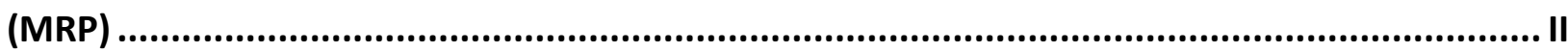

ABSTRACT

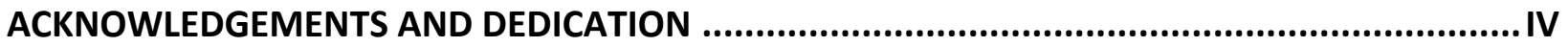

TABLE OF CONTENTS

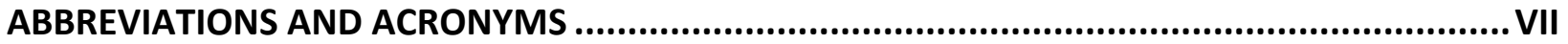

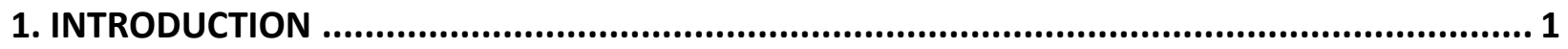

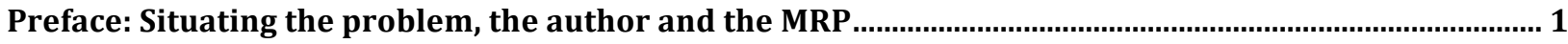

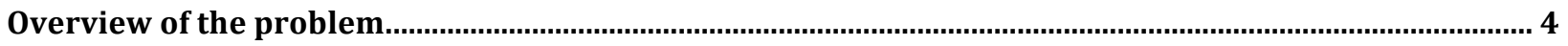

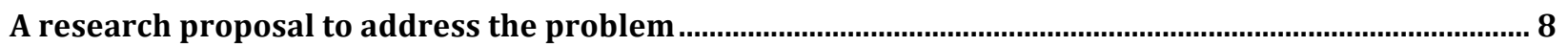

2. BACKGROUND CONTEXT AND PROPOSED RESEARCH PROJECT......................................... 10

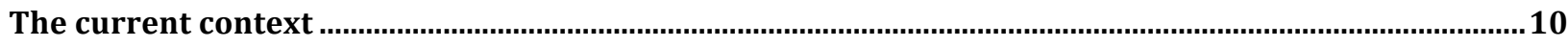

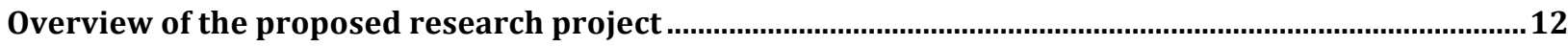

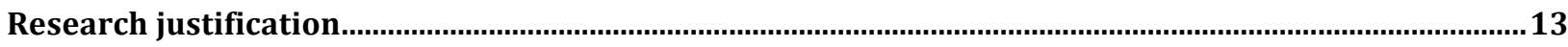

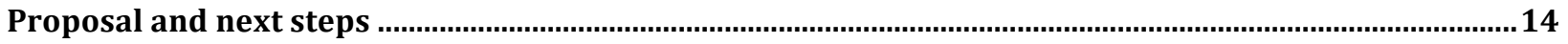

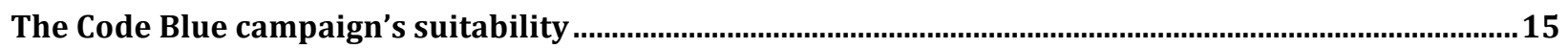

3. OVERVIEW OF RELEVANT TERMINOLOGY, CONCEPTS AND LITERATURE........................... 17

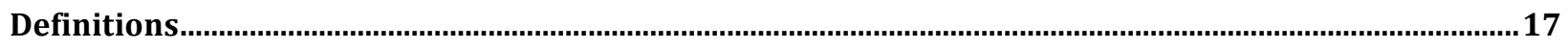

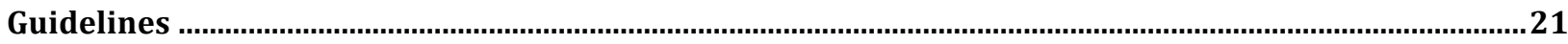

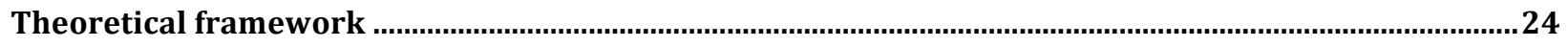

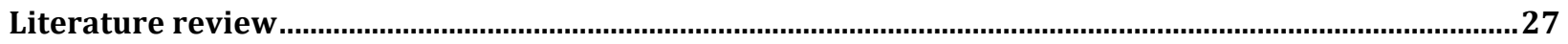




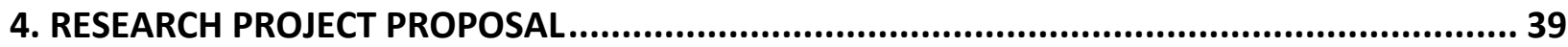

Research project structure

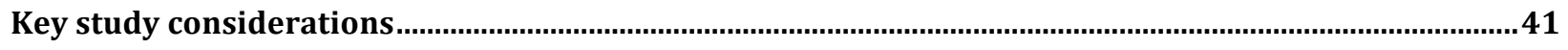

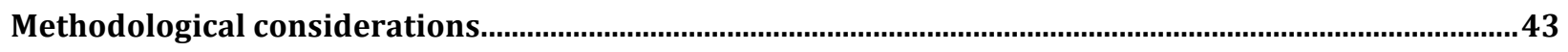

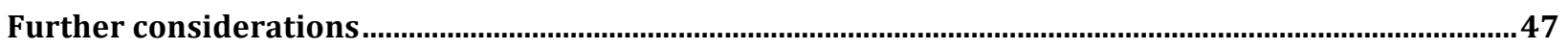

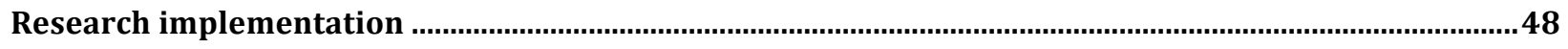

5. DISSEMINATION AND ADVOCACY STRATEGY ..................................................... 51

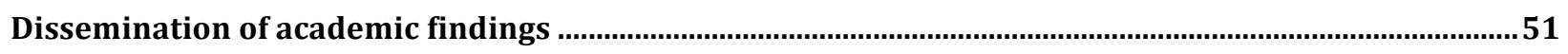

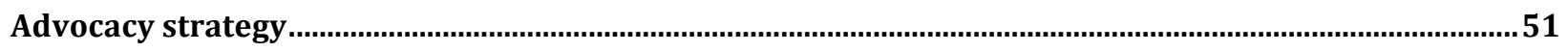

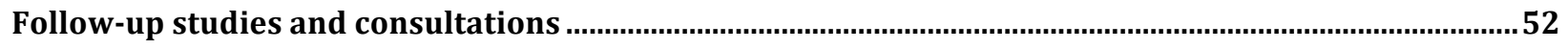

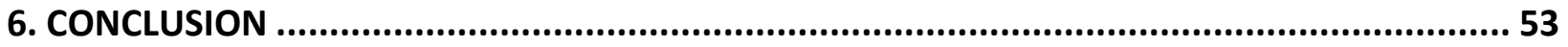

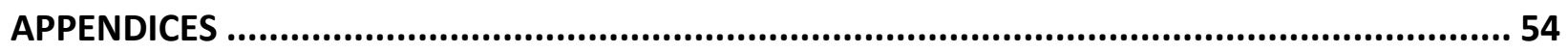

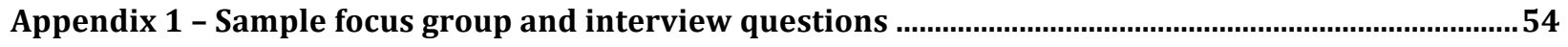

Appendix 2 - Proposed timeline (Overview)

Appendix 3 - About the proposed research coordinator............................................................... 57

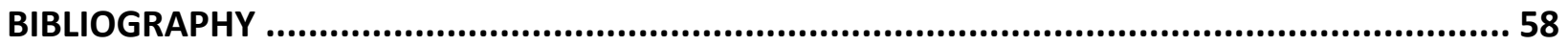




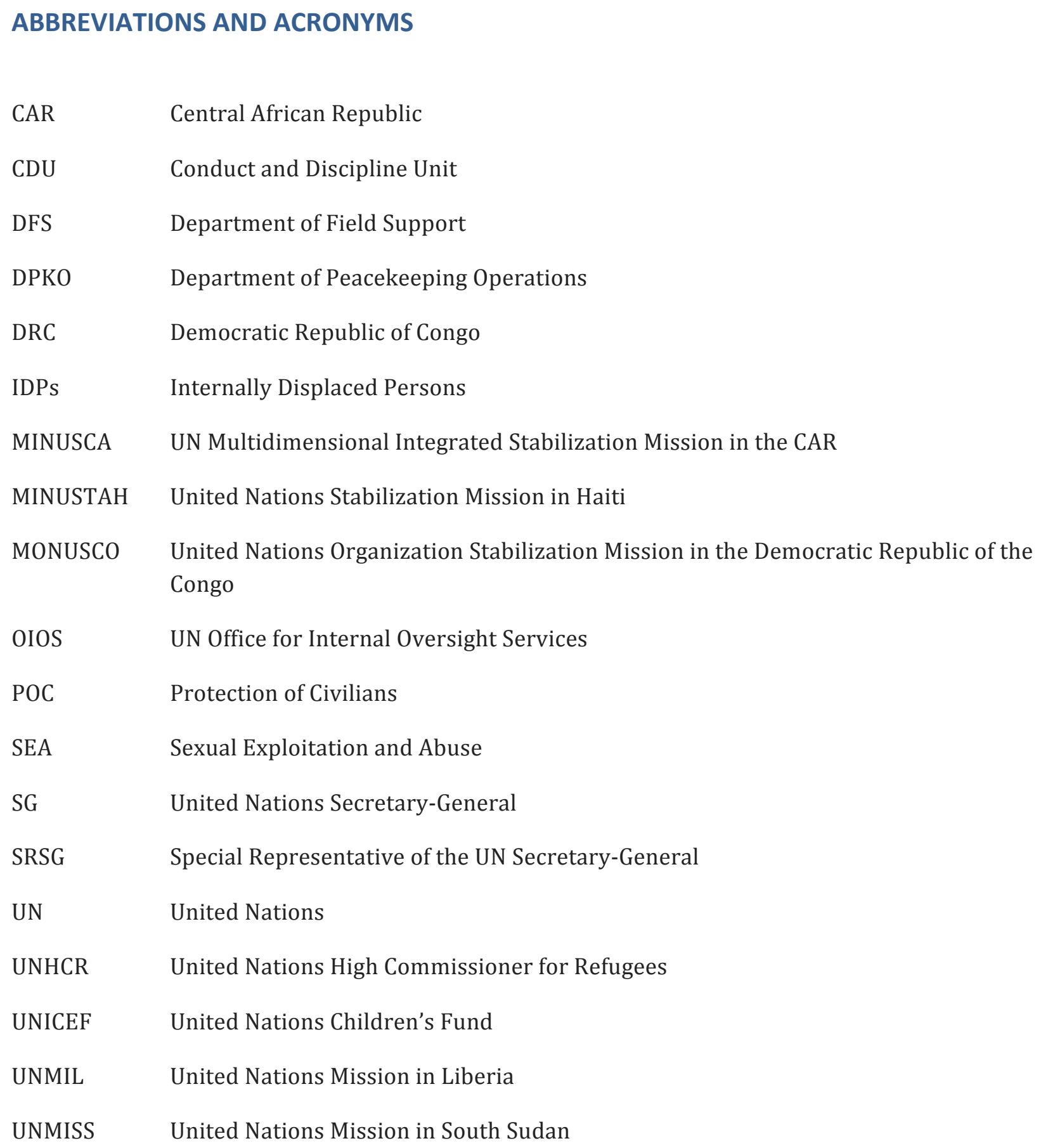




\section{INTRODUCTION}

\section{Preface: Situating the problem, the author and the MRP}

The boys, some of whom were orphans, disclosed sexual exploitation, including rape and sodomy, between December 2013 and June 2014 by French troops at a centre for internally displaced people at M'Poko airport in Bangui. The children described how they were sexually exploited in return for food and money. One 11-year-old boy said he was abused when he went out looking for food. A nine-year-old described being sexually abused with his friend by two French soldiers at the IDP camp when they went to a checkpoint to look for something to eat... The report describes how distressed the child was when disclosing the abuse and how he fled the camp in terror after the assault. ${ }^{1}$

Over the past year, the UN has faced a renewed crisis of confidence and conscience, stemming from allegations of sexual abuse against children in a displaced persons' camp by peacekeepers in the Central African Republic (CAR). These horrors were first exposed by AIDS-Free World's Code Blue campaign through a report in The Guardian in April 2015. Since then, multiple allegations - many involving internally displaced women and girls - have continued to be brought forward by journalists, civil society organizations and the UN, although primarily in CAR. ${ }^{2}$ The Code Blue campaign has continued to be at the forefront of these efforts, including by revealing the UN's failure to disclose shocking new allegations in CAR in March and April 2016. ${ }^{3}$ These latest allegations involve over a hundred reported victims, many of whom are minors and likely internally displaced persons (IDPs). Some of the victims were further displaced after their abuse as a result of community stigmatization. ${ }^{4}$

I am currently the project coordinator of "Code Blue," the advocacy campaign seeking to end impunity for sexual violence by UN peacekeeping personnel. The Code Blue campaign, which was formally launched by the non-governmental advocacy organization AIDS-Free World and its allies in May 2015, has re-ignited and sustained global attention to a long-standing problem. As

\footnotetext{
${ }^{1}$ Sandra Laville, 'UN Aid Worker Suspended for Leaking Report on Child Abuse by French Troops', The Guardian, 29 April 2015, sec. World news, http://www.theguardian.com/world/2015/apr/29/un-aidworker-suspended-leaking-report-child-abuse-french-troops-car.

${ }^{2}$ The UN's public statistics do not disaggregate victims by sex or displacement status, but see, for instance: Tom Esslemont, 'EXCLUSIVE - UN Peacekeepers Face New Sex Allegations in Central African Republic', Thomson Reuters Foundation, 11 November 2015, http://news.news.trust.org/item/20151111183717batnu/.

${ }^{3}$ AIDS-Free World, 'Shocking New Reports of Peacekeeper Sexual Abuse in the Central African Republic', 30 March 2016, http://www.codebluecampaign.com/press-releases/2016/3/30; AIDS-Free World, 'Another 41 Allegations of Peacekeeper Sexual Sex Abuse Undisclosed by the UN', 13 April 2016, http://www.codebluecampaign.com/press-releases/2016/4/13.

${ }^{4}$ AIDS-Free World, 'Shocking New Reports of Peacekeeper Sexual Abuse in the Central African Republic'.
} 
coordinator of the Code Blue campaign, I regularly work with academics, advocates, and UN decision-makers to advance the campaign's aims and objectives. ${ }^{5}$ My role also includes researching the problem of - and possible solutions to - impunity for "sexual exploitation and abuse" (SEA) ${ }^{6}$ by peacekeepers.

...there might be reporting biases depending on inter alia the location of SEA, the existence of reporting mechanisms, as well as international media and NGO attention. For these reasons, the reported SEA might be the "tip of the iceberg." 7

My research for the Code Blue campaign has uncovered the severity of under-reporting of sexual exploitation and abuse, despite the limited quantitative studies demonstrating the extent of this problem. The UN has spent years implying that sexual exploitation and abuse is diminishing because the number of annual reported allegations is generally decreasing. The UN attributes the decline in reported allegations to its reform efforts - despite its own assertions that even one case is "one too many." 8 Yet it is crucial to note that even the few studies that do exist demonstrate a wide gulf between what occurs on the ground and the "official" statistics produced by the UN. One striking study conducted in Liberia showed that an estimated 58,000 women were involved in transactional sex with UN personnel (prohibited as "sexual exploitation," as will be explored further in this paper) over a 9-year period ending in 2012, while the UN only recorded 69 allegations from 2007-2012 in Liberia. ${ }^{9}$

Over the course of research undertaken and consultations conducted with my Code Blue colleagues, we have identified multiple problems with the UN's data and the way it reports on allegations. It is difficult to independently verify the UN's data, not least because the UN - via its Conduct and Discipline Unit (CDU) - is the only body that comprehensively tracks, compiles and reports on the allegations. Furthermore, the UN has a vested interest in ensuring a downward trend in reported

\footnotetext{
${ }^{5}$ See appendix 2 for more "About the researcher."

6 "Sexual exploitation and abuse" or "SEA" is the terminology used by the UN to describe the phenomenon of prohibited sexual interactions with, or abuse against, local populations, as I explore in the "Definitions" section. Some forms of sexual exploitation (e.g. transactional sex or prostitution) may not be criminal actions in some jurisdictions. I use the more powerful term "sexual violence" and the UN's rather sanitized phrase "sexual exploitation and abuse" somewhat inter-changeably, depending on context.

${ }^{7}$ Ragnhild Nordås and Siri C. A. Rustad, 'Sexual Exploitation and Abuse by Peacekeepers: Understanding Variation', International Interactions 39, no. 4 (September 2013): 511-34, p. 530.

${ }^{8}$ United Nations Secretariat, 'Special Measures for Protection from Sexual Exploitation and Sexual Abuse: Report of the Secretary-General', 13 February 2015, http://www.un.org/ga/search/view_doc.asp?symbol=a/69/779.

9 Bernd Beber et al., 'Peacekeeping, International Norms, and Transactional Sex in Monrovia, Liberia', Working Paper, (2015), http://www.nyu.edu/projects/beber/files/Beber_Gilligan_Guardado_Karim_TS.pdf.
} 
allegations, to make it appear as though it is effectively handling the problem. It is therefore likely that many allegations of sexual exploitation and abuse are not counted in the overall total published by the UN.

In November 2015, a Thomson Reuters Foundation journalist reported that he had uncovered three new allegations of sexual exploitation and abuse in CAR. ${ }^{10}$ Those allegations were reported to the UN, and the Organization subsequently indicated that it was conducting investigations. Given my significant interest in, and work on, this area, I considered proposing research to expose additional incidents of sexual exploitation and abuse not reported to the UN in order to add to academic studies and journalistic accounts of the under-reporting problem. However, on reflection, I decided against this approach for a number of reasons. There are serious ethical considerations around "discovering" unreported sexual violence, particularly in situations where law enforcement and justice systems are inadequate, compromised or non-existent. Those issues are even more serious where minors are involved, especially where those minors are internally displaced within conflict zones and when they may lack parental or community support. Such "investigative" quantitative research remains an important area of study to be conducted by qualified and conscientious researchers. However, I determined that given my own training, skillset and role in the Code Blue campaign - alongside the limited opportunities to conduct ethically-sound field research - it would be more appropriate for me to propose qualitative research on the barriers to, and challenges associated with, reporting, to inform possible solutions to these problems. Of course, there are many inter-linked areas that require further research; this proposed research project would contribute to exploring one of the gaps identified.

This MRP is an "applied"11 paper, outlining a problem identified by an advocacy campaign and proposing field research to contribute to exploring and understanding the problem. It is anticipated that the MRP will form the foundation of a research project to be coordinated and commissioned by AIDS-Free World's Code Blue campaign, with the field research and subsequent analysis and publication of the findings to be carried out by independent academic researchers. In other words, the MRP shows how a proposed research project could provide insights to address a research problem and advance the goals of an advocacy campaign seeking to address these problems. As

\footnotetext{
10 Esslemont, 'EXCLUSIVE - UN Peacekeepers Face New Sex Allegations in Central African Republic'. ${ }^{11}$ According to the Immigration and Settlement Studies Master's Major Research Paper Guidelines (16 July 2014), "Papers in the applied category may engage any issue related to immigration and/or settlement in a policy, service-delivery or advocacy context... Typically, MRPs in this category strive to explore 'how' questions."
} 
such, my paper provides (i) the context, background and rationale for the proposed research; (ii) sets out key legal, ethical and methodological considerations, to be addressed further in the project design phase in conjunction with the academic research team; (iii) provides preliminary details on how the research project could be structured and conducted; and (iv) highlights the ways in which this research will be used to support and further advocacy efforts.

My goal is that the proposed research project outlined in this MRP will contribute an invaluable onthe-ground account of perspectives on the current system for reporting sexual exploitation and abuse by UN peacekeeping personnel. In particular, the proposed research will seek to identify systemic barriers to reporting as well as the challenges associated with decisions to formally report. By conducting focus groups and interviews with select community leaders, it will seek to give a voice to victims' perspectives through the experiences of those who support them, with a focus on the particular challenges faced by IDPs. Ideally, by comparing the experiences of communities in different peacekeeping contexts, researchers will be able to more credibly identify systemic problems that must be addressed. Supported by an advocacy campaign, the proposed research project will seek to identify the significant, systemic reforms necessary at the UN-level to adequately address this issue, and will lay the groundwork for further community consultations on the specific solutions envisaged. ${ }^{12}$

\section{Overview of the problem}

The recent revelations of widespread allegations of sexual exploitation and abuse in the Central African Republic (CAR) raise an underlying and crucial question about whether the problem is specific to the UN's MINUSCA mission in CAR, as senior UN officials have implied, or whether the current UN and international spotlight on CAR obfuscates abuses that persist in other peacekeeping operations. ${ }^{13}$ Undoubtedly, it is the latter: the latest allegations emerge against a backdrop of a long-standing awareness by the UN of the problem and rhetoric condemning it, stemming initially from scandals in Cambodia, Somalia and Bosnia in the 1990s. In 2002, the UN Secretary-General proclaimed:

Sexual exploitation and abuse by humanitarian staff cannot be tolerated. It violates everything the United Nations stands for. Men, women and children displaced by conflict or

\footnotetext{
12 Informed by conversations with AIDS-Free World co-Director Paula Donovan.

${ }^{13}$ AIDS-Free World, 'The UN Provided New Evidence Today That It Can't Solve Its Peacekeeper Sex Abuse Crisis from within', 29 January 2016, http://www.codebluecampaign.com/press-releases/2016/1/29-2.
} 
other disasters are among the most vulnerable people on earth. They look to the United Nations and its humanitarian partners for shelter and protection. ${ }^{14}$

This pronouncement came as part of a 2002 UN report investigating a massive scandal involving aid workers and peacekeepers abusing children in refugee camps in West Africa. The report found that "the conditions in the camps and in refugee communities in the three countries in question make refugees vulnerable to sexual and other forms of exploitation and such vulnerability increases if one is a female and young." 15 Prior to that scandal, in 1995, UNHCR (the refugee protection agency) released guidelines on Sexual Violence Against Refugees that outlined these risks and proposed steps to mitigate and address them. At the same time, civil society organizations had for years been sounding the alarm on concerns arising from the specific vulnerability of displaced children to sexual predators, including peacekeepers.

The problem of sexual exploitation and abuse by UN peacekeepers is inextricably linked to the vulnerability of displaced persons, whom those peacekeepers are frequently sent to protect. The UN has long recognized that "internal displacement implies a double vulnerability, to both the cause of displacement and to the tenuousness of well-being and security at points of destination."16 Indeed, Graça Machel's landmark 1996 study, Impact of Armed Conflict on Children, undertaken at the request of the UN Secretary-General (SG), is considered the first UN report to highlight sexual exploitation and abuse by peacekeepers and to focus international attention on the specific plight of displaced children. In six of the twelve countries surveyed for the report, "the arrival of peacekeeping troops has been associated with a rapid rise in child prostitution," and the report emphasizes that "girls in flight are even more vulnerable than usual to sexual abuse."17

The problem is compounded by the severe under-reporting of sexual violence alleged to have been committed by peacekeepers, which is likely even worse than the abysmally low rates of reporting of sexual violence in other contexts:

\footnotetext{
14 UN Secretary-General, 'Investigation into Sexual Exploitation of Refugees by Aid Workers in West Africa: Note by the Secretary-General', 11 October 2002, A/57/465, p. 1, http://www.refworld.org/docid/3deb32dd4.html.

15 Ibid, p. 4.

16 UN Secretary-General, 'Framework of Actions for the Follow-up to the Programme of Action of the International Conference on Population and Development Beyond 2014: Report of the Secretary-General' (United Nations, 12 February 2014), p. 165, https://www.unfpa.org/sites/default/files/pubpdf/ICPD_beyond2014_EN.pdf.

17 Graça Machel, 'Impact of Armed Conflict on Children' (United Nations, 1996), para 98, http://www.unicef.org/graca/a51-306_en.pdf.
} 
Given that victims of sexual violence worldwide find it difficult, unsafe, or futile to report sexual offenses to law enforcement, it would be unrealistic to assume that the allegations reported to the UN represent all or even most of the offenses committed.18

It is understood that the problem of under-reporting is even more complex in the context of displacement. Numerous studies have shown that "the true scale of sexual violence against refugees is unknown because numerous incidents are never reported."19 This can include because of difficulties knowing about reporting structures in a host site; language or cultural barriers; lack of trust in local authorities, organizations or the UN, groups that are responsible for receiving complaints; and stigma and discrimination by the host communities, to name a few.

It goes without saying that "under-reporting also perpetuates a lack of accountability for the abuse, since it underplays the scale of the problem." 20 Yet a near-total lack of criminal accountability for sexual violence by peacekeepers contributes to a sense of futility for victims, or worse, possible negative repercussions for those who do report these crimes to the UN or other authorities. ${ }^{21}$ As a result a vicious cycle perpetuates this problem, as would-be criminals are emboldened to engage in activities they might otherwise feel compelled to refrain from for fear of punishment. In contexts where armed conflicts are threatened, ongoing, or only recently quelled, with local protection and legal systems potentially weak, damaged or destroyed, a culture of impunity for sexual violence, including by those sent in to protect civilians, becomes the norm.

The UN has attempted to address the crisis over the years, yet fundamental flaws in its prevention, response and assistance mechanisms contribute to the general culture of impunity. In terms of the reporting context, the UN is mandated to report data on sexual exploitation and abuse by its own personnel, under its General Assembly Resolution 57/306 (which was issued following the UN's investigation into the allegations of abuse against refugees in West Africa in 2001-2002). Yet experts widely acknowledge that the UN under-reports the scope of the problem, as it only includes

\footnotetext{
${ }^{18}$ AIDS-Free World, 'AIDS-Free World - Supplementary Written Evidence' (UK House of Lords, Select Committee on Sexual Violence in Conflict, 13 November 2015), http://data.parliament.uk/writtenevidence/committeeevidence.svc/evidencedocument/sexual-violence-inconflict-committee/sexual-violence-in-conflict/written/24616.html. 19 UNHCR, 'Sexual Violence Against Refugees: Guidelines on Prevention and Response', 1995, http://www.unhcr.org/3b9cc26c4.html.

20 Corinna Csáky, 'No One to Turn To. The under-Reporting of Child Sexual Exploitation and Abuse by Aid Workers and Peacekeepers.' (Save the Children UK, 2008), p. 12.

http://www.savethechildren.org.uk/sites/default/files/docs/No_One_to_Turn_To_1.pdf.

${ }^{21}$ In one recently revealed alleged incident, community stigmatization led to girls being displaced from their communities: AIDS-Free World, 'Shocking New Reports of Peacekeeper Sexual Abuse in the Central African Republic'.
} 
those instances where victims have formally brought allegations to the UN's attention, whether directly or through indirect reporting mechanisms (primarily local non-governmental organizations). Moreover, its reporting system can count several incidents, or one incident involving multiple perpetrators and/or multiple victims, as one single "allegation," in a system that appears unique to the UN (which has no criminal justice mechanism itself). Furthermore, it does not include reports of abuse committed by peacekeepers who are authorized by the UN but are not directly serving under a UN banner, such as the French Sangaris troops accused of raping young boys in CAR in 2014. And while improvements are being rolled out in 2016, in relation to the timeliness and breadth of information the UN provides publicly on allegations and follow-up, it remains difficult to track and understand the data (for example, there are no case numbers nor are the incident dates listed). This further hampers transparency and accountability efforts.

In 2015, the UN committed to rolling out a "model complaint reception mechanism," to provide victims with "additional community-based reporting options, rather than having to report to the United Nations."22 This may well have been instigated in response to concerns about underreporting, and in the context of claiming better enforcement of its "zero tolerance" policy on sexual exploitation and abuse. Yet it is difficult to understand why the UN has taken so long to develop and roll-out such a model. Moreover, it is unclear whether the model is based on a thorough assessment or whether it is simply a "quick-fix" response to the many allegations that have been brought to light, and the public scrutiny and outcry over the past 12 months.

It will be important for civil society to assess whether the UN's new approach is actually improving the reporting experience and outcomes, particularly for vulnerable displaced girls, and contributing to ending impunity for these abuses. This is critical, because, anecdotally and beyond reported figures, peacekeeper sex with underage females is widespread, particularly in the context of displacement due to conflict. This persists despite these acts being both against the UN's rules, and constituting criminal actions in most jurisdictions.

Of course, sexual exploitation and abuse is also committed by humanitarian aid workers and other international actors, albeit no central statistics are logged that would enable research on that area. It is crucial, however, first to focus on UN peacekeepers before seeking to address the related issue of sexual exploitation and abuse committed by other international actors. The international

22 United Nations Secretariat, 'Special Measures Report (2015)'. 
community expressly mandates peacekeepers to protect civilians; and yet, they have long been notorious consumers of illegal sex:

Peacekeepers are reportedly among the highest paying customers for sex with children. They pay from US $\$ 5$ to $\$ 300$. Some peacekeepers are alleged to pool money to obtain a girl and then all have sex with the same child. ${ }^{23}$

Moreover, it may well be that rolling out "complaint reception mechanisms" to the community level does not enhance criminal accountability and access to justice for victims for a number of reasons. ${ }^{24}$ Depending on how the process is designed, having local civil society organizations receive complaints - rather than victims reporting directly to independent, impartial and trained law enforcement structures, whether local or international - could compromise this crucial first step of a potential criminal process. Furthermore, this arrangement may perpetuate the serious conflict of interest associated with the UN's involvement in receiving, handling and responding to allegations of crimes of sexual abuse by its own personnel. Even if community-based complaint reception structures are designed to be arms-length from the UN, the UN would presumably oversee and direct them, and victims may not see them as impartial or independent. These concerns coupled with the lack of transparency around these structures point to the need for further research into their design, including incorporating the perspectives of community leaders that support victims or potential victims.

\section{A research proposal to address the problem}

The key problem that this MRP seeks to address is:

How can advocates better understand and expose the significant barriers to, and challenges associated with, the UN's reporting structures for allegations of sexual exploitation and abuse by peacekeepers, particularly in the context of displacement, from the perspectives of community leaders that support victims, in order to consider and propose appropriate reforms?

The research project proposed as a method for addressing this problem is an independent, qualitative field study to elicit the perspectives of local civil society organization leaders and community members entrusted with the care and support of victims (or potential victims) of sexual

\footnotetext{
23 UNHCR and Save the Children UK, 'Sexual Violence and Exploitation - The Experience of Refugee Children in Guinea, Liberia and Sierra Leone', February 2002, p. 6, http://www.savethechildren.org.uk/sites/default/files/docs/sexual_violence_and_exploitation_1.pdf. 24 This section draws closely on multiple conversations with AIDS-Free World co-Director Paula Donovan.
} 
violence by peacekeepers, with a focus on displaced populations. The design includes focus group discussions complemented by targeted in-depth interviews. The proposed research, which ought to be undertaken in at least three peacekeeping contexts following a pilot study, is contextualized and outlined in detail in the sections that follow. A broad objective of the research project and the associated advocacy effort is to ensure better protection for, and support of, displaced girls, who remain amongst the most vulnerable to such sexual violence. Examining community-level perceptions of the barriers to, and challenges associated with, reporting sexual exploitation and abuse allegedly committed by UN peacekeeping personnel will support this objective, as those views are frequently absent from discussions. The research will form the foundation to critically and independently assess the UN's current and proposed reporting structures, with a view to recommending reforms informed by community perspectives. This will draw attention to the related lack of accountability for sexual exploitation and abuse, including criminal accountability for any actions that amount to crimes of sexual abuse, to support broader efforts to end impunity. 


\section{BACKGROUND CONTEXT AND PROPOSED RESEARCH PROJECT}

There is no child more vulnerable in the world today than a child internally displaced by armed conflict, forced to leave home and community behind. Not only do they fear for their lives when they flee for safety, but often face discrimination as their families search for means of survival. They... are frequently sexually assaulted or otherwise abused by unscrupulous adults, sometimes even by the aid workers or peacekeepers sent to protect them. 25

\section{The current context}

After the UN's inaction regarding child sex abuse by international peacekeepers in CAR was first exposed in 2015, human rights organizations and the media increased their focus on the problem, and brought to light new instances of child sex abuse in that country. ${ }^{26}$ This is largely because NGO staff and journalists, including investigative reporters, were dispatched to CAR following the initial exposé by the Code Blue campaign. In addition, victims of sexual abuse likely felt that reporting was less futile than in the past, since they could see the outside world and the UN taking seriously their reports of peacekeeper abuse, and were therefore more inclined to report past or new incidents. While there were no reported allegations of sexual exploitation or abuse in CAR in 2014,27 after AIDS-Free World's exposé in mid-2015, 17 allegations were reported by October 2015, with a total of 22 allegations reported in 2015, and at least 29 further allegations reported by 20 April 2016.28

The public outcry about the scandal in CAR led the UN to appoint Canadian Justice Marie Deschamps in June 2015 to head an external independent review into the UN's response to those allegations, as well as broader systemic issues about sexual exploitation and abuse by peacekeepers. Recognizing the particular vulnerability of displaced children, the independent

25 UN Secretary-General, 'Framework of Actions for the Follow-up to the Programme of Action of the International Conference on Population and Development Beyond 2014: Report of the Secretary-General'. ${ }^{26}$ For instance, Human Rights Watch published a report outlining new allegations, and Thomson Reuters Foundation and the Washington Post each detailed new allegations in investigative reports. Sources: Esslemont, 'EXCLUSIVE - UN Peacekeepers Face New Sex Allegations in Central African Republic'; Kevin Sieff, 'The Growing U.N. Scandal over Sex Abuse and "peacekeeper Babies"', Washington Post, 27 February 2016 , http://www.washingtonpost.com/sf/world/2016/02/27/peacekeepers/.; Human Rights Watch, 'Central African Republic: Rape by Peacekeepers', Human Rights Watch, 4 February 2016, https://www.hrw.org/news/2016/02/04/central-african-republic-rape-peacekeepers.

27 Note that some of these allegations may have involved sexual abuse that took place in 2014; the UN's public data currently does not specify the date of the alleged abuse, as allegations generally refer to the date they were first recorded by the UN.

${ }^{28}$ United Nations, Conduct and Discipline Unit, 'Status of Allegations, Investigations and Actions (Sexual Exploitation and Abuse)', 24 April 2016, https://cdu.unlb.org/Statistics/DetailedOverviewofAllegationsfrom2015onward/StatusofAllegationsInvestig ationsandActionsSexualExploitationandAbuse.aspx. 
review found that the crimes of sexual violence "are heinous violations of the human rights of some of the most vulnerable people on earth—children in a displaced persons camp in the midst of an armed conflict and humanitarian crisis—by those mandated to protect them." 29 However, that review focused more on the UN response to sexual abuse by non-UN peacekeepers, particularly focused on the incidents in CAR, and was therefore not the full, thorough systemic review for which advocates had called.

In the months while the review was ongoing and then following on from the critical report published by the "CAR Panel" in December 2015, the world's attention remained focused on CAR. Indeed, the UN has announced each new allegation at its daily noon briefings for journalists in New York. Yet, allegations in other countries hosting peace operations have all but been ignored. Although the 2015 figures show 69 allegations in total - including 16 in DRC, 9 in Haiti, and 6 in Liberia $^{30}$ - only some of the recent allegations in DRC have been reported on specifically by the UN in its communications to journalists. ${ }^{31}$

While the media attention is focused on CAR, it is not the biggest peacekeeping mission in terms of size; nor does CAR have the highest number of internally displaced persons, although the numbers are significantly high. ${ }^{32}$ It is therefore likely that sexual exploitation and abuse by UN peacekeeping personnel is rampant in other missions, even where the UN reports no or few allegations. For example, South Sudan appears as an anomaly. In that country sexual violence is rampant by parties to the conflict and in the general society; ${ }^{33}$ there is a large peacekeeping mission, with just slightly

\footnotetext{
${ }^{29}$ Marie Deschamps, Hassan B. Jallow, and Yasmin Sooka, 'Taking Action on Sexual Exploitation and Abuse by Peacekeepers: Report of an Independent Review on Sexual Exploitation and Abuse by International Peacekeeping Forces in the Central African Republic', 17 December 2015, p. 17, http://www.un.org/News/dh/infocus/centafricrepub/Independent-Review-Report.pdf. 30 United Nations, Conduct and Discipline Unit, 'Statistics: Allegations by Category of Personnel Per Year (Sexual Exploitation and Abuse)', n.d., https://cdu.unlb.org/Statistics/AllegationsbyCategoryofPersonnelSexualExploitationandAbuse/Allegationsb yCategoryofPersonnelPerYearSexualExploitationandAbuse.aspx.

31 United Nations News Service, 'UN News - UN Sexual Misconduct Investigation in DR Congo Finds Violations and Cases of Abuse', UN News Service Section, 4 April 2016, http://www.un.org/apps/news/story.asp?NewsID=53609\#.Vx5dHDYrLx4.

32 Nearly 300,000, out of a population of about 5.4 million, as of December 2015, along with about 24,000 refugees, asylum seekers and returnees. Sources: UNHCR, '2015 UNHCR Country Operations Profile - Central African Republic', December 2015, http://www.unhcr.org/pages/49e45c156.html.; Internal Displacement Monitoring Centre, 'Global Figures', n.d., http://www.internal-displacement.org/global-figures. 33 UN Office for the High Commissioner for Human Rights, "South Sudan: UN Report Contains "searing" Account of Killings, Rapes and Destruction', 11 March 2016, http://www.ohchr.org/EN/NewsEvents/Pages/DisplayNews.aspx?NewsID=17207\&LangID=E.
} 
more personnel than in $\mathrm{CAR} ;{ }^{34}$ and displaced persons reside in close proximity to peacekeepers in "protection of civilians" (POC) camps (another risk factor as populations become dependent on peacekeepers for assistance and protection) ${ }^{35}$ - yet, the UN reported no allegations for 2015.36 Some of this context is in contrast to Nordås and Rustad's empirical findings, that

SEA was more frequently reported in situations with lower levels of battle-related deaths, in larger operations, in more recent operations, the less developed the country hosting the mission, and in operations where the conflict involved high levels of sexual violence. ${ }^{37}$

One might argue that the lack of a spotlight on peacekeeper sexual violence in South Sudan is the reason for the lack of reported allegations, along with weak reporting structures. As a large mission with a similar mandate to the CAR mission, and troops from the same countries, ${ }^{38}$ it could be expected that more cases would otherwise emerge ${ }^{39}$ (at present, the UN is only now implementing a code of conduct for staff working in POC camps ${ }^{40}$ ). Crucial questions must be asked, about South Sudan and about other peacekeeping missions. Do victims and their allies know how to report sexual exploitation and abuse? Are adequate reporting structures even in place? Have victims otherwise perceived that reporting is futile, or dangerous?

\section{Overview of the proposed research project}

In light of these reflections, this paper proposes that the Code Blue campaign commissions and coordinates original research on the reporting context for allegations of sexual exploitation and abuse by UN peacekeeping personnel. I propose that the research focuses on CAR and other comparable countries hosting peacekeeping missions where there are large internally displaced populations. The research will enable a systemic analysis of the barriers to, and challenges associated with, formal reporting.

\footnotetext{
${ }^{34}$ UN Department of Peacekeeping Operations, 'Peacekeeping Fact Sheet', 29 February 2016, http://www.un.org/en/peacekeeping/documents/bnote0216.pdf.

35 Nordås and Rustad, 'Sexual Exploitation and Abuse by Peacekeepers'.

${ }^{36}$ United Nations, Conduct and Discipline Unit, 'Statistics: Allegations by Category of Personnel Per Year (Sexual Exploitation and Abuse)'.

${ }^{37}$ Nordås and Rustad, 'Sexual Exploitation and Abuse by Peacekeepers'.

${ }^{38}$ For instance, 29 countries have military and/or police personnel in both MINUSCA and UNMISS, of which 8 countries faced at least one allegation in 2015. United Nations, Conduct and Discipline Unit, 'Status of Allegations, Investigations and Actions (Sexual Exploitation and Abuse)'.

${ }^{39}$ In the first three months of 2016, with significant attention on this issue at the UN including through the adoption of a new Security Council resolution (2272), there have already been 31 allegations involving at least 56 alleged perpetrators and 37 victims, including 2 in Haiti, 2 in DRC, 1 in South Sudan, and 1 in Libya. Source: Ibid.

${ }^{40}$ Discussions with an unnamed aid worker formerly based in South Sudan, February 2016.
} 
The proposed project consists of primary research in camps for internally displaced persons ("IDP camps"). The focus will be on the perceptions of local civil society organizations and other community leaders. The research participants will ideally be those who are in positions of responsibility for providing support to victims of peacekeeper sexual abuse, or to vulnerable populations who are potential victims. Specifically, the research will obtain insights into considerations of decisions around formal reporting, as well as experiences and outcomes when formal reports have been made. For example, the research will explore the research participants' role in, and experiences of, helping victims to formally report, whether to the UN, designated community structures, or local authorities. In terms of the design, researchers will conduct focus groups to better understand the context and determine the most appropriate individuals to interview, followed by in-depth interviews with selected participants. The study will assess whether the UN's recent outreach efforts and stated measures to roll-out model community-based reporting mechanisms are working, and whether they are even desirable, from the perspectives of the communities themselves. It will offer insights into any problems with the structures and initial insights into possible solutions.

The research will involve working with local partner organizations based in the host countries (likely CAR, DRC and South Sudan), which will provide input into the study's design, host focus groups, and facilitate the involvement of local researchers. Methodological and additional considerations are discussed in greater detail in Section Four.

\section{Research justification}

From the perspective of victims and vulnerable populations: Greater awareness of, and attention on, the issues identified should cause the UN (and others who receive initial reports of peacekeeper sexual abuse) to critically examine flaws in the current reporting structures. It should also lead to better support for communities and local civil society groups that are involved in supporting victims, particularly in the context of IDP camps. Participation in the research should help empower community leaders to raise concerns on reporting structures with local authorities and/or the UN. In the longer term, and accompanied by additional research and advocacy, this project should force decision-makers to implement more appropriate, victim-centered reporting structures. Ultimately, these efforts should improve the prospect of reported allegations being more effectively and efficiently investigated, independent from the UN, leading to more successful prosecutions. Ideally, complementary measures to identify risks and prevent such abuses from occurring will be reenergized through this process. 
From a victim-centred advocacy perspective: Building on the above, the general public, media, UN leaders and Member State decision-makers will likely be more outraged by the problem, invest greater resources to fix it, and be more open to deeper systemic changes ${ }^{41}$, if the specific barriers and challenges that vulnerable populations and their community support systems face in reporting abuses are better exposed and understood. The proposed research also provides an opportunity for academics and civil society to critically assess the UN's efforts to roll out community-based complaint mechanisms, and examine whether they actually encourage formal reporting and/or lead to more access to justice. This is especially crucial because the UN's internal assessments are rarely made public, as is the case with details of such new mechanisms.

From an academic perspective: Limited field research exists on sexual exploitation and abuse by peacekeepers, with only a few studies examining the particular vulnerability of displaced persons to sexual abuse by peacekeepers, and/or the specific barriers to and challenges associated with reporting, as the literature review outlines below. ${ }^{42}$ The proposed research builds on a recent study that found that 231 Haitians involved in transactional sex did not know about the UN mission's reporting mechanism or hotline, and only 7 knew that the mission had a policy on sexual activities by peacekeepers. ${ }^{43}$ It will be useful to compare these findings with the perspectives of community leaders, who might be expected to be more familiar with the UN rules and procedures. The study will complement recent human rights investigations by groups such as Human Rights Watch in CAR, ${ }^{44}$ journalistic expositions, and earlier NGO reports. Researchers seeking to influence policy recognize that additional studies, with findings published in peer-reviewed journals, help strengthen the case for additional resources and policy reform measures.

\section{Proposal and next steps}

This applied MRP lays the foundation for the proposed research project by: (i) outlining the rationale for and necessity of such a study, and setting in in its appropriate historical, theoretical

\footnotetext{
${ }^{41}$ For examples of the reforms proposed, see: AIDS-Free World, 'Time for Dramatic Changes to End Peacekeeper Sexual Abuse', 26 January 2016, http://www.codebluecampaign.com/pressreleases/2016/1/26.

42 Several key studies focus on sexual exploitation and abuse by aid workers, sometimes also mentioning peacekeepers, but not as the main focus of study.

${ }^{43}$ Athena Rebecca Kolbe, “It's Not a Gift When It Comes with Price”: A Qualitative Study of Transactional Sex between UN Peacekeepers and Haitian Citizens', Stability: International Journal of Security and Development 4, no. 1 (2015), http://www.stabilityjournal.org/article/view/sta.gf/.

${ }^{44}$ Human Rights Watch, 'Central African Republic: Rape by Peacekeepers', 4 February 2016, https://www.hrw.org/news/2016/02/04/central-african-republic-rape-peacekeepers.
} 
and scholarly context; (ii) considering preliminary research design and methodological considerations that will be addressed with the research team, along with ideas on how to operationalize the project; and (iii) setting out the planned dissemination and advocacy strategy to ensure that the research is applied to support reform efforts.

The purpose of the proposal is to enable AIDS-Free World's Code Blue campaign to consider the key aspects of the proposed research project, which it will then ideally implement by dedicating and marshalling the necessary resources. It is proposed that the campaign will also play a key role in helping to disseminate the findings as part of its ongoing advocacy. Nonetheless, to ensure the credibility of the findings, the field research should be entrusted to independent academics with the required experience and expertise (and drawing on the support of trained social workers, and legal and other experts, as needed). The Code Blue campaign could nonetheless provide support to both the execution of the research (for instance, by providing a research coordinator to support the project and by connecting researchers to local contacts in peacekeeping missions) and to the independent academic publication of the findings (for instance, by offering comments on the draft write-up of the findings and discussing the practical application of recommendations). The campaign's considerable contribution, beyond this, would be to undertake the associated advocacy to expose and contextualize the results in ways that make them understandable to a broad public and ensure they are acted upon by decision-makers.

\section{The Code Blue campaign's suitability}

The Code Blue campaign has had previous successes in supporting the dissemination of research by academics and translating findings for a wider audience. For example, when it first heard of expert research commissioned by the UN (but not made available to the public), it released the final report via an open letter to Ambassadors to the UN in New York. ${ }^{45}$ This helped establish the campaign's credibility as a well-connected source of information and as an advocate for greater transparency on the problem, and disseminated the expert's findings more broadly.

The Code Blue campaign is run by small core team of staff from AIDS-Free World, led by coDirectors Paula Donovan and Stephen Lewis, who have extensive experience as former senior UN officials, and are respected expert advocates on sexual violence and UN reform. The campaign is well-connected to a broad network of academics, journalists, advocates, legal experts and UN

${ }^{45}$ AIDS-Free World, 'UN Experts' Unseen Peacekeeping Report: Sexual Exploitation and Abuse', 16 March 2015, http://aidsfreeworld.org/Newsroom/Press-Releases/2015/Open-Letter-to-UN-Missions.aspx. 
insiders (current and former) who can be called upon for information, advice and analysis. In 2016, the Code Blue campaign received a substantial grant from the Dutch Postcode Lottery. The funding proposal for the grant set out that the campaign would coordinate and disseminate academic research. As such, the proposed research could be funded at least in part by the campaign. 


\section{OVERVIEW OF RELEVANT TERMINOLOGY, CONCEPTS AND LITERATURE}

\section{Definitions}

The following section outlines several key concepts and definitions, drawing on the UN's official terminology, as well as analysis - by the Code Blue campaign and other experts - of some of the shortcomings of those definitions. This background is crucial for understanding the context of the research and ensuring that it is situated within current academic, policy and NGO literature and work.

Sexual exploitation and abuse: Sometimes referred to by its acronym, SEA, this is the UN's terminology for prohibited sexual behaviour targeting the local population by UN and associated personnel. There is some debate as to whether it can also refer to acts committed by a UN staff member against another UN staff member. For the purposes of the paper, the former definition suffices. I have selected not to use the acronym, and often use the term 'sexual violence' instead, following Lutz et al.'s excellent characterization:

The shorthand (SEA, pronounced S, E, A) is widely used, but both the long and the short hand term have the problem that they fail to communicate anything like the reality and severity of much of what goes by that name or acronym, such as an adult male peacekeeper sodomizing an 11 year old girl, already orphaned and impoverished by war; coercing sex by offering money or food to hungry teenage girls for oral sex; paying boys to act as pimps; verbal sexual abuse, or having a sexual relationship with a young woman who hopes thereby to escape her situation but is abandoned when the peacekeeper leaves. ${ }^{46}$

Sexual abuse: The SG's Bulletin defines sexual abuse as "the actual or threatened physical intrusion of a sexual nature, whether by force or under unequal or coercive conditions." 47 All sexual activity with minors, including sexual exploitation, is sexual abuse.

Sexual exploitation: The SG's Bulletin defines sexual exploitation as "any actual or attempted abuse of a position of vulnerability, differential power, or trust, for sexual purposes, including, but not limited to, profiting monetarily, socially or politically from the sexual exploitation of another." 48

\footnotetext{
46 Catherine Lutz, Matthew C. Gutmann, and Keith Brown, 'Conduct and Discipline in UN Peacekeeping Operations: Culture, Political Economy and Gender', 19 October 2009, pp. 1-2, http://papers.ssrn.com/sol3/papers.cfm?abstract_id=2323758.

${ }^{47}$ United Nations Secretariat, Secretary-General's Bulletin: Special Measures for Protection from Sexual Exploitation and Sexual Abuse, 2003, Section 1, http://www.un.org/ga/search/view_doc.asp?symbol=ST/SGB/2003/13.

48 Ibid, s. 1
} 
Host country: A country hosting a peacekeeping mission, also referred to as the local country or the research location in this paper.

Beneficiaries of assistance: The SG's Bulletin "strongly discourages," but does not prohibit, sexual relations with "beneficiaries of assistance." 49 In peacekeeping contexts, beneficiaries are generally understood to mean all nationals of the host country as well as refugees residing there. As this term is not defined in the UN Bulletin, it can be a source of confusion.

Allegations: According to the UN's CDU, which tracks and records allegations in UN peacekeeping:

An allegation is an unproven report of alleged misconduct, which may not necessarily lead to an investigation if there is insufficient information to warrant an investigation. Allegations are counted per individual, unless the number and/or identities of individuals have not been confirmed. In that case, allegations would be counted per incident."50

As noted above, it is common that one "allegation" includes several incidents, or one incident involving multiple perpetrators and/or multiple victims. The CDU's website lists only allegations of sexual exploitation and abuse by UN peacekeeping personnel, while the SG's annual Special Measures report also includes allegations by other UN personnel not supported by the peacekeeping structure. However, it appears that not all of the UN's funds, programmes and agencies are covered by that report.

Minors: "Article 1 of the Convention on the Rights of the Child, of 1989, defines a child as every human being below the age of 18 years unless, under the law applicable to the child, majority is attained earlier. The same definition is used in article 2 of the African Charter on the Rights and Welfare of the Child, of 1999."51

Countries have different laws in terms of the age of consent for sexual activity and for reporting child sex abuse. For instance, while Canada's laws define minors as all those under the age of 18, Canada's official age of consent, under its criminal laws, is 16 . Sexual activity involving 16- and 17year olds is illegal if it includes activity considered "exploitative" (e.g. with persons in positions of

\footnotetext{
${ }^{49}$ Ibid, s. 3.2(d)

50 United Nations, Conduct and Discipline Unit, 'Overview of Statistics', accessed 28 March 2016, https://cdu.unlb.org/Statistics/OverviewofStatistics.aspx.

51 UN Secretary-General, 'Investigation into Sexual Exploitation of Refugees by Aid Workers in West Africa', $p$. 7.
} 
authority or trust) or involving prostitution or pornography.52 Moreover, in Canada there are laws on mandatory reporting to child protection officials for suspected child sex abuse, determined on a provincial or territorial level.

As Lutz et al. point out, "The legality of prostitution, the age of consent and the age of marriageability all vary around the world." ${ }^{3}$ Nonetheless, section 3.2(b) of the SG's Bulletin clarifies that all those under 18 are considered minors with regards to its policy on sexual exploitation and abuse, regardless of local laws, making such acts against the UN's administrative rules (and subject to administrative sanctions) at a minimum: "Sexual activity with children (persons under the age of 18 ) is prohibited regardless of the age of majority or age of consent locally. Mistaken belief in the age of a child is not a defence." 54 Even in conflict situations where local laws and child protection structures may be weak, damaged or non-existent, the UN should uphold and model the highest standards.

Transactional sex: Although not explicitly labelled as such in the SG's Bulletin, section 3.2(c) outlines the UN's definition: an “exchange of money, employment, goods or services for sex, including sexual favours or other forms of humiliating, degrading or exploitative behaviour, [which] is prohibited. This includes any exchange of assistance that is due to beneficiaries of assistance." 55 One study notes, in discussing "selling sex," that "the term 'transactional sex' is also used for this form of having sex for money, etc., but both terms are problematic as they suggest a situation of equal exchange, which is certainly not the case for children, and not for many women."56

While "exploitation" is sometimes used to describe transactional sexual relationships between peacekeepers and minors, if they are below the age of consent to sexual relations, this should be properly referred to as sexual abuse. This has important implications for correctly characterizing and investigating all sexual acts with those below the age of consent as being likely criminal conduct.

\footnotetext{
52 Department of Justice Government of Canada, 'Frequently Asked Questions: Age of Consent to Sexual Activity', 11 February 2015, http://www.justice.gc.ca/eng/rp-pr/other-autre/clp/faq.html. ${ }^{53}$ Lutz, Gutmann, and Brown, 'Conduct and Discipline in UN Peacekeeping Operations,' p. 7.

${ }^{54}$ Note: there is an exception for 'legal' marriages. United Nations Secretariat, Secretary-General's Bulletin: Special Measures for Protection from Sexual Exploitation and Sexual Abuse, s. 3.2(b)

55 Ibid, s. 3.2(c).

${ }^{56}$ Save the Children UK, 'From Camp to Community: Liberia Study on Exploitation of Children', Discussion Paper, (2006), p. 5, https://www.essex.ac.uk/armedcon/story_id/000381.pdf.
} 
Peacekeeping: The terms peace operations and peacekeeping missions are used interchangeably in this paper. Current peacekeeping operations now often include mandates that make them operationally war-like, when there is no 'peace' to keep. This research project deals specifically with the 16 peacekeeping operations currently led by the UN, nine of which are in Africa. ${ }^{57}$

Peacekeepers: For this project, the term "peacekeepers" encompasses both uniformed and civilian personnel involved in peacekeeping missions, also referred to as "UN peacekeeping personnel." In terms of reporting on allegations of sexual exploitation and abuse, the CDU website lists five categories: military; police, civilian; other (consultants and contractors); and unknown. ${ }^{58}$ The jurisdictional considerations associated with the different categories of personnel are discussed below. ${ }^{99}$ While some studies look only at sexual abuses by military or uniformed personnel, the Code Blue campaign has uncovered that, as a proportion of personnel on mission, the number of accusations against civilian personnel is greater on average than for military personnel since 2007.60

Jurisdictional considerations: The current structures and rules governing sexual abuse by peacekeepers pose an inherent challenge: the onus is largely on the victim to identify the category of personnel of the accused, if there are no other witnesses, as different investigative and criminal processes and authorities apply to different categories of personnel. Troop-contributing countries (TCCs) have exclusive criminal jurisdiction over their respective military personnel, meaning such troops are immune from local (host state) jurisdiction. However, if the accused is a civilian or police personnel, the UN appears to reserve the right to decide whether their immunity from local prosecution (which is "functional" in nature, thus only applying to acts committed in their official capacity) should be deemed not to apply. If immunity is found not to apply, the UN then informs local (host state) authorities of the alleged crime - in the case of the study, the authorities in CAR,

\footnotetext{
57 These include peacekeeping operations in the following states/regions: Western Sahara; Central African Republic; Mali; Haiti; Democratic Republic of the Congo; Darfur (Sudan); Golan; Cyprus; Lebanon; Abyei (Sudan); Kosovo; Liberia; South Sudan; India and Pakistan; Côte d'Ivoire; Middle East. United Nations, Department of Peacekeeping Operations, 'Current Peacekeeping Operations', accessed 27 March 2016, http://www.un.org/en/peacekeeping/operations/current.shtml.

${ }^{58}$ United Nations, Conduct and Discipline Unit, 'Statistics: Allegations by Category of Personnel Per Year (Sexual Exploitation and Abuse)'.

${ }^{59}$ Some studies and reports discussed in the MRP define "peacekeepers" as military or uniformed personnel (military and police) only.

${ }^{60}$ AIDS-Free World, 'AIDS-Free World - Supplementary Written Evidence'.
} 
DRC or South Sudan.61 Yet, UN police personnel are often repatriated well before the host country has been appraised of the crime. Moreover, the sending country (e.g., the country of the repatriated police officer) may not have extraterritorial jurisdiction for certain crimes committed abroad, and transnational investigations are inherently more challenging.

This confusing jurisdictional arrangement poses a fundamental double standard: different rules apply to different categories of personnel. There is an extra burden placed on victims for correctly identifying the accused, in order to trigger an appropriate investigation by the country of nationality of the alleged perpetrator or the host state, depending on the category of personnel, if justice is to be served.

Refugees: Refugees are individuals who have crossed an international border in search of protection. Legally, they are guaranteed international protection under the 1951 Refugee Convention. "Refugees" technically refers to only those who have been granted status under the Convention on a recognized ground; in this paper, I include asylum seekers as part of the broader category.

IDPs: Internally displaced persons (IDPs) have left their homes due to conflict or natural disaster, similar to refugees, but have not crossed an international border. Legally, their governments are responsible for their protection, as is outlined in greater detail below.

\section{Guidelines}

Displaced persons, especially children, are amongst the most vulnerable to peacekeeper sexual abuse. Given this, the following section expands on the definitions above by reviewing guidelines, policies and laws that cover displacement and child protection, and those that address the tension between maintaining confidentiality for research participants and mandatory reporting laws and guidelines relating to suspected child sex abuse. It also draws on the research methods and practices identified in the key relevant studies.

\section{Institutional and international protection of refugee and internally displaced children}

A core set of documents codify international human rights, humanitarian and refugee law as it relates to displaced children, most of which have widespread acceptance and therefore can be said to represent customary international law.

\footnotetext{
61 To do this, the UN conducts a preliminary "investigation" to determine whether the allegation is "credible." This is problematic, as it has no legal jurisdiction over the crimes, and does not make clear the standard of proof used to determine credibility.
} 
Refugee children: As noted in the definitions section, refugees are guaranteed rights through the 1951 Refugee Convention, which states hosting refugees are bound to uphold. In the African context, there is broader legal protection under the 1969 Convention Governing the Specific Aspects of Refugee Problems in Africa, interpreted as more accommodating of mass refugee situations. Globally, the 1989 Convention of the Rights of the Child contains specific articles relating to the protection of refugee children. In 1993, UNHCR adopted its Policy on Refugee Children, followed by its Guidelines on Protection and Care the year after.62 As noted above, UNHCR followed this with complementary guidance on Sexual Violence Against Refugees in 1995.

Internally displaced children: In the international context, states are obligated under international human rights law to uphold the rights of all citizens and permanent residents, including those displaced within their borders. In situations of armed conflict, international humanitarian law applies as well. The protections found in the Convention on the Rights of the Child apply as well, and generally supersede all national law. Further, in the African context, the 1999 African Charter on the Rights and Welfare of the Child applies. In situations of mass displacement due to conflict or other emergency situations, including those where peacekeepers are dispatched, the UN has a protection mandate: UNHCR is responsible for protection of IDPs generally, and UNICEF has a specific duty for the protection of children. ${ }^{6}$

\section{Tension between confidentiality and child protection}

As has been referenced above, an important consideration for the proposed research project is the tension between maintaining confidentiality of all information provided by research participants, and obligations, in accordance with national laws and ethical standards, relating to mandatory disclosure of child sex abuse to identified child protection authorities. In practice, where applicable, this means that any research participants whose confidentiality cannot be guaranteed by researchers with regards to the relevant authorities because of mandatory disclosure laws must be informed about this through the consent process. My assessment, as outlined below, is that these issues are not sufficiently explored in the academic literature or in NGO reports that relate to the

\footnotetext{
${ }^{62}$ Human Rights Watch, 'Forgotten Children of War: Sierra Leonean Refugee Children in Guinea', 1 July 1999 , https://www.hrw.org/report/1999/07/01/forgotten-children-war/sierra-leonean-refugee-children-guinea. 63 While not legally binding, the Responsibility to Protect doctrine was largely developed in response to failures of governments to protect citizens, including IDPs.
} 
subject of sexual exploitation and abuse in peacekeeping contexts, which present additional challenges and complexities. 64

A general principle is that parental/guardian consent is required for research. Older youth may be exempt from this requirement, particularly for research regarding sexual activity if national laws set the age of sexual consent below 18. In addition, in some jurisdictions mandatory reporting of child sex abuse only applies to children below a certain age. Most UN operational guidance addresses these concepts, as they relate to children in conflict and/or displacement situations, in rather general terms. ${ }^{65}$ The SG's 2003 Bulletin defines specific obligations for UN personnel to report allegations "via established reporting mechanisms," and prohibits all sexual activity with children under 18 regardless of local laws (with an exception for 'legal' marriages), but does not specifically address reporting to host country child protection authorities. ${ }^{66}$ Given the UN's critical role in strengthening and/or rebuilding host country capacity as part of peacekeeping efforts, including in terms of the rule of law, this is a major omission.

The relevant studies that relate to research with children (which are discussed in greater detail in the next section) do not generally explain the specific methodology and protocols used for considering or handling this balance between maintaining confidentiality for child participants and any requirements to report abuse uncovered for the first time. For example, Csáky's 2008 study notes (p. 3) that participants were advised that disclosure of abuse would not be acted on without permission of the individual, though notes its 'Safeguarding Children' policy that mandates reporting, prioritising the best interests of the child (p. 12).67 A 2006 Save the Children report, which organized focus groups and interviews with adults and children under the context of incomegenerating activities, does not discuss the confidentiality / reporting issue, but does note in its recommendations that international NGOs should report all cases to the "relevant government authority." 68 The original 2002 UNHCR/Save the Children report on refugees in West Africa

\footnotetext{
64 The issue will require further legal consideration for the ethics review process that is beyond the scope of this MRP.

65 Examples include: World Health Organization, 'WHO Ethical and Safety Recommendations for Researching, Documenting and Monitoring Sexual Violence in Emergencies', 2007, http://www.who.int/gender/documents/OMS_Ethics\&Safety10Aug07.pdf; UNHCR, 'Sexual Violence Against Refugees'; UNHCR, 'Refugee Children: Guidelines on Protection and Care', 1994, http://www.unicef.org/violencestudy/pdf/refugee_children_guidelines_on_protection_and_care.pdf. 66 United Nations Secretariat, Secretary-General's Bulletin: Special Measures for Protection from Sexual Exploitation and Sexual Abuse.

67 Csáky, 'No One to Turn To'.

68 Save the Children UK, 'From Camp to Community: Liberia Study on Exploitation of Children'.
} 
likewise does not discuss its specific methodology on this issue. ${ }^{69}$ The subsequent OIOS-led investigation in 2002 notes assurances were provided on the confidentiality of the information received (para. 7), and that some cases were referred to the NGOs involved for follow-up (e.g. paras. 17, 19). ${ }^{70}$ Finally, Atwood et al.'s 2011 study does not discuss any considerations or protocols for mandatory reporting of child sex abuse, and notes the results were confidential. It nonetheless obtained ethics board approval from universities in both the US and Liberia, where the study was conducted, considered a best practice for my proposed research project. ${ }^{71}$

Other studies appear to circumvent this concern by involving only adult research participants. ${ }^{72}$ Reports by Human Rights Watch on sexual exploitation and abuse by peacekeepers appear to have interviewed women and girls whose abuse had likely already been reported, or the NGO took it upon themselves to report abuses to the UN (perhaps seeing the UN as the de facto authority for child protection, although this could be considered problematic from a capacity-building perspective). ${ }^{73}$

The discussion above informs my decision to not involve minors in the proposed research, and to interview community leaders rather than victims themselves. A protocol will be put in place in terms of steps to take and support to be provided in the event that new allegations are uncovered through the proposed research, as is described in Section 4.

\section{Theoretical framework}

The "boys will be boys" attitude will continue to taint the debate until approaches to sexual exploitation are changed to reflect the fact that sexual exploitation and abuse is a problem of misuse of power and infractions meriting disciplinary action rather than a matter of consensual sexual relations between equal partners. ${ }^{74}$

\footnotetext{
${ }^{69}$ UNHCR and Save the Children UK, 'Sexual Violence and Exploitation - The Experience of Refugee Children in Guinea, Liberia and Sierra Leone'.

${ }^{70}$ UN Secretary-General, 'Investigation into Sexual Exploitation of Refugees by Aid Workers in West Africa'.

${ }^{71}$ Katharine A. Atwood et al., 'Transactional Sex among Youths in Post-Conflict Liberia', Journal of Health, Population and Nutrition, 2011, 113-22.

72 Kolbe, “'It's Not a Gift When It Comes with Price”'; Beber et al., 'Peacekeeping, International Norms, and Transactional Sex in Monrovia, Liberia'.

${ }^{73}$ Human Rights Watch, 'The Power These Men Have Over Us: Sexual Exploitation and Abuse by African Union Forces in Somalia', 8 September 2014, https://www.hrw.org/report/2014/09/08/power-these-menhave-over-us/sexual-exploitation-and-abuse-african-union-forces; Human Rights Watch, 'Central African Republic: Rape by Peacekeepers'.

74 Sarah Martin, 'Must Boys Be Boys?: Ending Sexual Exploitation and Abuse in UN Peacekeeping Missions' (Refugees International, October 2005), p. 6, http://www.humanrightsvoices.org/assets/attachments/articles/1890_must_boys_be_boys.pdf.
} 
Lutz et al. observe that UN peacekeeping officials, and some UN Member States, often see sexual exploitation and abuse as an issue of "indiscipline," and as a function of unchecked male human nature and sexual desires that can be contained and limited (including by such measures as "appropriate" recreational facilities for peacekeepers), rather than of skewed gender dynamics. This paper views rape as "a function of power, domination and gender inequality," 75 which is consistent with the majority of NGO reports and academic studies on sexual exploitation and abuse by aid workers and peacekeepers, including in the context of displacement. Undoubtedly, "UN peacekeeping missions... impact unevenly on civilian populations in post-conflict environments, especially in relation to gender and security,"76 in part due to gendered power differentials. This can include the negative "unintended consequences" of peacekeeping, such as sexual exploitation and abuse. ${ }^{77}$ While reaffirming the accused's rights to justice, this proposal is rooted in a victimcentred approach that recognizes that concern for victims has long been more rhetoric than reality: the UN-commissioned Expert Team expressed concern about a "culture of extreme caution with respect to the rights of the accused, and little accorded to the rights of the victim."78

Further, this paper holds that sexual violence by peacekeepers - including the rape of male children, who are often feminized in such abuses ${ }^{79}$ - is influenced by the hyper-masculine, militarized culture of peacekeeping in war zones. ${ }^{80}$ Indeed, there is an inherent conflict:

Given military peacekeepers earlier socialization into the hyper-masculine military, what is required of peacekeepers in the field may be fraught with tension... For example, peacekeeping operations are argued to require impartiality, sensitivity and empathy, attributes that may have been discouraged by traditional military training. ${ }^{81}$

This culture is often unchecked due to a culture of impunity resulting from an absence of law and order, both in the host country and, more importantly, in the flawed design of UN peacekeeping

\footnotetext{
${ }^{75}$ Lutz, Gutmann, and Brown, 'Conduct and Discipline in UN Peacekeeping Operations'.

${ }^{76}$ Paul Higate and Marsha Henry, 'Engendering (In)security in Peace Support Operations', Security Dialogue 35, no. 4 (1 December 2004): 481-98, p. 482.

77 Vanessa Kent, 'Protecting Civilians from UN Peacekeepers and Humanitarian Workers: Sexual Exploitation and Abuse', in Unintended Consequences of Peacekeeping Operations, ed. Chiyuki Aoi, Cedric de Coning, and Ramesh Thakur (United Nations University Press, 2007), 44-66.

78 Catherine Lutz, Thelma Awori, and Thapa, General Paban J., 'Final Report: Expert Mission to Evaluate Risks to SEA Prevention Efforts in MINUSTAH, UNMIL, MONUSCO and UNMISS', 3 November 2013, p. 3, http://aidsfreeworld.org/Newsroom/Press-

Releases/2015/ /media/Files/Peacekeeping/2013\%20Expert\%20Team\%20Report\%20FINAL.pdf.

79 Informed by conversations with Paula Donovan, co-Director, AIDS-Free World.

${ }^{80}$ Martin, 'Must Boys Be Boys?'

${ }^{81}$ Higate and Henry, 'Engendering (In)security in Peace Support Operations'.
} 
accountability structures, which fail to ensure institutional or individual criminal responsibility. It is also entrenched through the culture of silence common to tight-knit militaries. ${ }^{82}$

To address the latter, enhanced training of peacekeepers on gender "issues" and sexual exploitation and abuse, and an increase in the number of female peacekeepers, is sometimes argued as necessary. ${ }^{83}$ Yet, neither of these measures will be sufficient if criminal accountability systems cannot work. In line with the deterrence theory of criminality, this paper holds that the prosecution of crimes of sexual violence will serve as the best deterrent to future crimes, ${ }^{84}$ as it will help dispel belief in impunity. Going further, feminist legal perspectives challenge conventional legal notions of "objectivity and impartiality" and instead "insist on the importance of gender relations as a category of analysis." 85 Aligning with feminist advocates that seek greater accountability for individual perpetrators of crimes of sexual abuse in the international context, it recognizes that flawed institutional structures and failures of leadership contribute to impunity - without forming an excuse for inaction. Indeed, advocates can play a key role in re-assessing and challenging these systems from a gender perspective, to make them more effective for victims of sexual violence who seek justice.

The global women, peace and security agenda can serve as a useful framework for insisting on a gendered analysis of sexual violence in conflict settings. In particular, the agenda can help draw attention to the increased vulnerability of girls and women displaced by conflict, and provide a reference point to connect advocates seeking gender-sensitive reform. Focusing on the gender dimensions of (in)security, including the roles played by mostly male peacekeepers in conflict and post-conflict zones, ${ }^{86}$ broadens consideration of the multiple facets of the problem. It helps shed light on how sexual exploitation and abuse destroys the effectiveness of peacekeeping operations and, more broadly, damages the UN's credibility, including its credibility on addressing sexual violence in conflict. Yet, the paper takes a holistic view of sexual violence as a manifestation of gendered power dynamics, resulting from patriarchal structures that result in women's unequal

\footnotetext{
82 Elizabeth F. Defeis, 'UN Peacekeepers and Sexual Abuse and Exploitation: An End to Impunity', Wash. U. Global Stud. L. Rev. 7 (2008), p. 185.

83 Sabrina Karim and Kyle Beardsley, 'Explaining Sexual Exploitation and Abuse in Peacekeeping Missions: The Role of Female Peacekeepers and Gender Equality in Contributing Countries', Journal of Peace Research 53, no. 1 (January 2016): 100-115.

${ }^{84}$ Kelly Neudorfer, 'Reducing Sexual Exploitation and Abuse: Does Deterrence Work to Prevent SEAs in UN Peacekeeping Missions?', International Peacekeeping 21, no. 5 (2014): 623-41.

85 Hilary Charlesworth, 'Feminist Methods in International Law', The American Journal of International Law 93, no. 2 (1999): 379-94.

${ }^{86}$ Higate and Henry, 'Engendering (In)security in Peace Support Operations'.
} 
power across societies, and not just in conflict. Such inequalities are reflected in legal systems local, national and international - and in multilateral institutions. These must be reformed to promote and enhance criminal accountability for sexual violence, elevating this crime's seriousness and recognizing the damage and destruction that it causes to individuals, families and societies, as well as to other institutions.

In addition, an intersectional approach must be considered in discussions of the effect of militarized masculinities on gender relations in peacekeeping contexts, for instance class, race, ethnicity and nationality ${ }^{87}$ It is also important to consider that a neo-colonial, ethno-racial "othering" of populations in need of protection (largely in African countries or other formerly colonized states) comes into play a role in the rhetoric around peacekeeper sexual abuse. For instance, one manifestation is the reluctance to immediately hand over the investigation of crimes by civilian and police peacekeepers to local authorities, even where the local law enforcement and judicial capacity is considered functioning (in the present system, military troops remain under the exclusive jurisdiction of the troop-contributing country, under agreements signed between the UN and the host state, and the UN and the contributing state). While there may be legitimate concerns about the capacity, impartiality and independence of local authorities, these concerns should not result in an absence of accountability. At a minimum, the UN should be reinforcing local capacities through its peacekeeping efforts, including any criminal investigation of its own personnel, as appropriate, or designing alternative solutions. ${ }^{88}$ The paper considers that states should retain a primary role in protecting civilians and prosecuting crimes committed against them and/or by their nationals, though constrained by evolving international norms and laws. Where states fail in these protection duties, they can be called to account, with the multilateral system bearing responsibility to ensure the protection of civilians.

\section{Literature review}

This section first outlines a selection of the relevant field studies that the research project builds on. Next, drawing from these and other studies and sources, it addresses key questions and findings that form the background and context of the proposed study.

87 Ibid.

88 Informed by conversations with Paula Donovan, AIDS-Free World co-Director. 


\section{Relevant studies}

A key recent study is Kolbe's qualitative study of transactional sex with peacekeepers in Haiti (2015), which was commissioned by OIOS. Notably, it excludes children, although some adult participants reported on incidents that occurred when they were minors. It is particularly relevant as it was undertaken at the request of OIOS, which provided funding and input into its design, yet the academic findings were independently published after OIOS had released a summary of the results for its own evaluation report. A similar structure between the research team and the Code Blue campaign is envisaged for my proposed research project. Furthermore, Kolbe's study shows how academic research can support advocacy efforts: the study uncovered 231 Haitians who "admitted" to transactional sex with peacekeepers, causing OIOS to note that "each instance of transactional sex would classify as prohibited conduct under the 2003 bulletin, thus demonstrating significant underreporting" by the UN's official figures. ${ }^{89}$ This received significant media coverage, leading to an outcry at the UN, particularly in the influential budget (fifth) committee.

The study specifically sought to "provide feedback on the process of reporting abuse and/or exploitation by peacekeepers to the authorities, including feedback on decision-making by victims and their families involved in this process as well as aspects which may help or hinder reporting," a theme likewise featured in my proposed research project. ${ }^{90}$ Moreover, it found that of the 231 research participants interviewed,

few knew of any policy prohibiting sexual harassment and none knew of a MINUSTAH reporting mechanism or of the MINUSTAH hotline. Seven interviewees knew that MINUSTAH had a policy regarding sexual activities by peacekeepers. Of these, four said they had heard that you could make a report to MINUSTAH but that they believed the report was only for rape. Three other interviewees were unsure of what is prohibited. Two interviewees thought there might be a policy against prostitution but were not positive about it. 91

It will be important to compare these perceptions with the knowledge and understanding of representatives of civil society organizations and community leaders through my proposed study. They could be expected to be more informed about the policies and structures; if they are not, the UN's plan to roll-out community-based complaint reception mechanisms will need to be assessed alongside outreach and training efforts.

${ }^{89}$ Kolbe, “'It's Not a Gift When It Comes with Price”".

90 Ibid.

${ }^{91}$ Ibid. 
Atwood et al.'s qualitative study provides insight into the context of transactional sex attitudes and behaviours amongst youth in Liberia, though in a post-conflict society (unlike CAR) where an extensive "peacekeeping economy" has taken hold. ${ }^{92}$ The study is limited in scale and does not focus specifically on peacekeepers. Beber et al.'s quantitative household survey done in Liberia also looks at prohibited (but not necessarily criminal) "transactional" relationships, with a focus on adults rather than youth. Beber et al. estimate that 58,000 women were involved in transactional sex with UN personnel over a 9-year period ending in 2012, while the UN only recorded 69 allegations from 2007-2012 in Liberia. ${ }^{93}$ This has parallels to Kolbe's study that clearly shows the extent of under-reporting by the UN, and participants' general disinterest in reporting transactional sex. ${ }^{94}$ Of course, given the financial incentives associated with transactional relationships, it is not surprising that many women (and children) would choose not to report. Some have argued for the UN's regulatory focus to be on preventing, and addressing impunity for, crimes of sexual violence by peacekeepers, rather than attempting to prohibit all sexual relations between locals and peacekeepers, thereby also emphasizing women's agency. ${ }^{95}$

Several studies address the specific vulnerabilities faced by displaced children, particularly girls. Human Rights Watch's 1999 investigation into Sierra Leonean refugees in Guinea addresses sexual violence risks faced by refugee girls, but only refers to aid workers drawn from the refugee population and not UN staff, international aid workers or peacekeepers. ${ }^{96}$ Csáky's 2008 report for Save the Children covers both aid workers and peacekeepers in Southern Sudan (now South Sudan), Cote d'Ivoire and Haiti. It held focus groups with adults and children, but did not focus on displaced persons; in fact, it specifically avoided refugee camps as research sites (no explanation is given for this choice). Nonetheless, its focus group questions are a good starting point for the proposed research project (see Appendix 1), and it is the most relevant study in terms of examining the communities' perceptions with regards to the reporting context. ${ }^{97}$ Although it deals with sexual exploitation and abuse by aid workers and not peacekeepers, Lattu's account of interviews with

\footnotetext{
92 Atwood et al., 'Transactional Sex among Youths in Post-Conflict Liberia'.

93 "UN personnel" includes other agency staff apart from peacekeepers, although peacekeepers comprised the majority of UN personnel in Liberia at the time of the study. Beber et al., 'Peacekeeping, International Norms, and Transactional Sex in Monrovia, Liberia'.

${ }^{94}$ Kolbe, "'It's Not a Gift When It Comes with Price"'.

95 Gabrielle Simm, Sex in Peace Operations (West Nyack: Cambridge University Press, 2013).

96 Human Rights Watch, 'Forgotten Children of War'.

97 Csáky, 'No One to Turn To'.
} 
refugee beneficiaries, including on barriers to reporting, is nonetheless relevant. ${ }^{98}$ Martin's 2005 report for Refugees International focuses specifically on peacekeepers (military and civilian) in Liberia and Haiti. Martin conducted interviews with women (not girls) in IDP and refugee camps, which, similar to Csáky, informs its significant advocacy recommendations - a model for my proposed research. ${ }^{99}$ In addition, a 2006 Save the Children report on sexual exploitation and abuse in Liberia focuses specifically on IDPs (and those formerly displaced), and examines abuses by aid workers and peacekeepers. ${ }^{100}$

\section{Generalized findings from the literature and relevant reports}

The major results of the key studies noted above and other sources are captured in the sections that follow.

\section{Why do peacekeepers rape, and get away with it?}

Over the years, through different reform efforts, the UN has attempted to regulate sexual relations between peacekeepers and local populations, as well as addressing sexual exploitation and abuse. In other words, it has attempted to "shape and regulate peacekeeper masculinity in terms of sexual expression (or aggression) and its potential impact on members of the local population."101 However, this regulation can cause more confusion: for example, the UN Bulletin "discourages" consensual relations between peacekeepers and locals, while not outright banning it. 102 The relatively limited literature offers varied reasons when it comes to understanding and explaining why peacekeeping personnel continue to engage in prohibited sexual exploitation and abuse. This paper holds that rape is not a crime of sex, but rather an abuse of power, and studies have shown that sex is generally not the "dominant" issue in sexual violence.103 Csáky notes that "peacekeepers are capable of exerting particular influence over the communities in which they serve, especially over children and young people." 104 They are more likely to come from countries that hold

\footnotetext{
${ }^{98}$ Kirsti Lattu, 'To Complain or Not to Complain: Still the Question' (HAP - Humanitarian Accountability Partnership International, June 2008), http://www.keepingchildrensafe.org.uk/sites/default/files/to_complain_or_not_to_complain_beneficiaries_p erceptions_of.pdf. ${ }^{99}$ Martin, 'Must Boys Be Boys?'

100 Save the Children UK, 'From Camp to Community: Liberia Study on Exploitation of Children'. 101 Higate and Henry, 'Engendering (In)security in Peace Support Operations'. p. 487. 102 United Nations Secretariat, Secretary-General's Bulletin: Special Measures for Protection from Sexual Exploitation and Sexual Abuse.

${ }^{103}$ See in particular: A. N. Groth, W. Burgess, and L. L. Holmstrom, 'Rape: Power, Anger, and Sexuality', The American Journal of Psychiatry 134, no. 11 (November 1977): 1239-43.

104 Csáky, 'No One to Turn To', p. 8.
} 
discriminatory or disrespectful views towards women ${ }^{105}$ and a culture of impunity for sexual violence. With military personnel comprising the bulk of UN peacekeeping personnel, there is no doubt that the negative masculinities associated with militaries are transferred into the peacekeeping realm, 106 where a "wall of silence" can form to protect its members, and extend to civilians on mission. ${ }^{107}$ This is compounded by TCCs' retention of exclusive jurisdiction over their troops, as there is a risk that different contingents will have different standards, training and discipline for troops regarding sexual exploitation and abuse.

Some of the risk factors cited for sexual violence by peacekeepers include a lack of recreational facilities; drug and alcohol abuse; serving in a hostile context far from home; and separation from intimate partners. This paper holds that these views are demeaning to the vast majority of men who serve on peacekeeping missions with honour. ${ }^{108}$ However, the broad regulation of all forms of peacekeeper sex, including discouragement of consensual sexual relations through the SG's Bulletin, arguably puts in place grey zones that add confusion and weaken respect for the UN's zero tolerance policy. ${ }^{109}$ This contributes to a weak accountability and legal regime - which, more critically, includes different disciplinary rules and associated investigative processes for different categories of personnel - and contributes to a culture of impunity that enables predators. ${ }^{110}$ Furthermore, when it comes to military peacekeepers, "the risk of prosecution is viewed as slight given the existence of immunity and the difficulties associated with gathering evidence admissible in the troop-contributing country."111

Civilian peacekeepers have 'functional' immunity that applies only to acts carried out in relation to their duties. Thus, while their immunity is not theoretically applicable for crimes of sexual violence, it also contributes to the culture of impunity by making it seem as though UN staff are above the

\footnotetext{
105 Ibid, p, 8.

106 Paul Higate, 'Peacekeepers, Masculinities, and Sexual Exploitation', Men and Masculinities 10, no. 1 (2007): 99-119.

107 Defeis, 'UN Peacekeepers and Sexual Abuse and Exploitation'; see also Martin, 'Must Boys Be Boys?' and UNHCR and Save the Children UK, 'Sexual Violence and Exploitation - The Experience of Refugee Children in Guinea, Liberia and Sierra Leone'.

108 Informed by conversations with Paula Donovan, AIDS-Free World co-Director.

109 Kathleen Jennings, 'Protecting Whom?: Approaches to Sexual Exploitation and Abuse in UN Peacekeeping Operations' (Fafo, 2008).

110 Defeis, 'UN Peacekeepers and Sexual Abuse and Exploitation'.

111 Muna Ndulo, 'Sexual Abuse and Sexual Exploitation in Conflict Situations as a Security Risk', EInternational Relations, 22 June 2015, http://www.e-ir.info/2015/06/22/sexual-abuse-and-sexualexploitation-in-conflict-situations-as-a-security-risk/.
} 
law.112 The fact that their country of nationality exerts little if no influence on them when they are serving with the UN, and the UN's involvement in the early stages of investigating crimes alleged by them, further contribute to their ability to commit crimes with relative impunity.

Empirical studies show that when there are high levels of sexual violence in the local population, there is a higher risk for sexual violence by peacekeepers and others in the international community - and vice versa.113 Furthermore, host countries "that have laws prohibiting spousal rape are slightly more likely than countries that do not have such laws to see reports of SEA."114 This is perhaps because these progressive laws empower citizens and authorities alike to report other forms of sexual abuse. Of course, reporting is only one indicator of sexual violence happening, and an absence of reports does not mean that sexual violence is not occurring.

One risk factor for rape is limited or total lack of social control, where the "perceived cost" such as social stigma or punishment is low. ${ }^{115}$ If one assumes that reported abuses (can) lead to punishment, then if sexual violence by peacekeepers is under-reported, this creates the perception that perpetrators can "get away" with it. This results in a vicious circle, creating the semblance of a more permissive environment for other potential perpetrators, and fuelling a culture of impunity.

\section{What are the specific vulnerabilities and protection needs of displaced persons, and especially girls?}

Recognizing that sexual abuse and exploitation are a consequence of unequal power relationships; a dynamic that is often exacerbated during humanitarian crises characterized by widespread violence, mass displacement, and the breakdown in family structures, social and value systems; and noting with distress, the involvement of humanitarian workers, officials and other persons working closely with refugee populations... -UNHCR Executive Committee conclusion from 2003.116

Nordås and Rustad's empirical research has shown that displaced persons have a higher likelihood of experiencing sexual exploitation and abuse. ${ }^{117}$ Persons residing in IDP or refugee camps have a

\footnotetext{
112 AIDS-Free World, 'Democracy Now Interview with Paula Donovan', 2 July 2015, http://www.codebluecampaign.com/latest-news/2015/7/16.

113 Nordås and Rustad, 'Sexual Exploitation and Abuse by Peacekeepers'.

114 Ibid.

115 Russell (1984) developed a four-factor model, which suggests preconditions that allow rape to occur. These are (1) factors creating a predisposition or a desire to rape, (2) factors reducing internal inhibitions against acting out this desire, (3) factors reducing social inhibitions against acting out this desire, and (4) factors reducing the potential victim's ability to resist or avoid the rape. Source: Ibid.

116 UNHCR, Conclusion on Protection from Sexual Abuse and Exploitation, 2003, http://www.unhcr.org/3f93b2c44.html.

117 Nordås and Rustad, 'Sexual Exploitation and Abuse by Peacekeepers'.
} 
great reliance on peacekeepers and/or aid workers for security and material assistance, thus bringing them into closer contact with potential perpetrators. ${ }^{118}$

Save the Children's "fieldwork suggests that already vulnerable children are particularly at risk of sexual abuse and exploitation by peacekeepers and aid workers...[including] children displaced from their home communities."119 It also sets out that "perpetrators of abuse arguably target orphans and separated children, since they are least likely to report them to the authorities,"120 in line with the reasoning above that the fact that peacekeepers "getting away" with sexual violence gives a semblance of permissiveness, increasing the risk of it occurring.

Having established that refugees are vulnerable to sexual violence, UNHCR lists the following categories amongst the top at risk: "unaccompanied women, lone female heads of household, unaccompanied children, [and] children in foster care arrangements."121 Individuals are particularly vulnerable if they lack legal documentation. The design of camps can also put displaced persons at greater risk, particularly if they must travel outside the camp to collect firewood or other survival items, or if there is a lack of adequate lighting, foot traffic, or other design challenges. Moreover, field studies show that girls are more likely to be victimized than boys, ${ }^{122}$ with OIOS finding that "single young women who have lost their supporting family structures in the wars are among those most at risk." 123 This is reflected in UNHCR's protection guidelines that note the risk heightens by "the collapse of traditional societal support mechanisms," including for the protection of vulnerable persons, such as the absence of male members of the community. ${ }^{124}$ UNHCR also makes clear:

Refugee girls are often even more vulnerable than refugee boys. In some cultural and social contexts, girls are less valued than boys and, consequently, are more often subject to neglect and abuse. Their participation in education programmes is often prematurely curtailed. They are subject to sexual abuse, assault and exploitation in greater numbers than are boys. ${ }^{125}$

\footnotetext{
118 Kelly Neudorfer, Sexual Exploitation and Abuse in UN Peacekeeping: An Analysis of Risk and Prevention Factors (Lexington Books, 2014), p. 79.

119 Csáky, 'No One to Turn To', p. 7.

120 Ibid, p. 7.

121 UNHCR, 'Sexual Violence Against Refugees'.

122 Ibid, p. 7.

${ }^{123}$ UN Secretary-General, 'Investigation into Sexual Exploitation of Refugees by Aid Workers in West Africa'. 124 UNHCR, 'Sexual Violence Against Refugees'.

125 UNHCR, 'Refugee Children: Guidelines on Protection and Care'.
} 
Are internally displaced persons more vulnerable than refugees?

There can be different ways of looking at this question, which is important as it helps guide the choice of research participants and locations in countries where there are both high numbers of IDPs and refugees. The UN's 2002 report on sexual exploitation of refugees in West Africa notes UNICEF's suggestion that the investigation should have included IDPs, as they are also vulnerable to exploitation. The UNHCR/Save the Children-UK assessment that prompted that report notes "the level of sexual violence experienced by abducted girls and in IDP situations is much higher than those in refugee camps, especially where awareness campaign have been conducted [in refugee camps] as part of the sexual and gender-based violence program."126

The humanitarian system that is designed to support populations dealing with conflict or other emergencies is increasingly providing greater protection to IDPs, with UNHCR now seeing them as a core part of their protection mandate. ${ }^{127}$ Nonetheless, refugees in many host countries are likely to be better protected than IDPs given the guarantees provided by international refugee law and the fact that the UN is more directly involved in their care and protection. Indeed, from a legal perspective, IDPs are primarily dependent on their own state to provide protection, even though it may be that the authorities in power are hostile to the ethno-religious or other affiliation of the IDP. As such, and given the more limited research conducted to date, the proposed research project focuses on the specific protection concerns of IDPs vis-à-vis sexual exploitation and abuse.

\section{Why might girls choose to engage in transactional sex?}

All sexual activity with minors under the age of 18 is a crime of sexual abuse in most jurisdictions (or at least if it is exploitative in nature), and is forbidden under the UN's rules. However, it is known that some girls chose to engage in sexual relationships and/or participate in transactional sex with peacekeepers. While being clear that this must not be condoned given inherent power differentials and a high potential for sexual violence, understanding the motivation of some girls to engage in transactional sex may help design strategies to prevent it and encourage reporting. It may also help in efforts to provide guidance to the local civil society organizations and community

\footnotetext{
${ }^{126}$ UNHCR and Save the Children UK, 'Sexual Violence and Exploitation - The Experience of Refugee Children in Guinea, Liberia and Sierra Leone', p. 13.

127 “UNHCR's original mandate does not specifically cover IDPs, but because of the agency's expertise on displacement, it has for many years been protecting and assisting millions of them, more recently through the "cluster approach." Under this, UNHCR has the lead role in overseeing the protection and shelter needs of IDPs as well as coordination and management of camps." Source: UNHCR, 'Internally Displaced People', accessed 27 March 2016, http://www.unhcr.org/pages/49c3646c146.html.
} 
leaders that support these girls, including on decisions to report. In a 2011 focus group study with adolescent youth in Liberia, "there was a general recognition among girls that their sexuality had value on the sexual exchange market and provided certain financial freedoms, status, and power."128 In a similar vein, the UN notes that some refugee women and girls enter into relationships with aid workers (including some drawn from the local population) with the expectation or hope of additional assistance, noting the "abject poverty" of camp life and the absence of skills training or employment meant they felt compelled to augment the "inadequate" aid they were receiving. ${ }^{129}$ A comparative empirical study finds that poorer countries have higher rates of reported sexual exploitation and abuse. ${ }^{130}$ Some families may condone or even encourage their daughters' involvement in transactional sex because of poverty, although with an expectation that the girls should be discrete so as to preserve their (and their families') reputations; this helps explain under-reporting. 131 There may also be pressure from peers. ${ }^{132}$ Nonetheless, none of this negates the fact that transactional sex can also fuel sexual violence, particularly when girls attempt to negotiate the terms, including condom use, which is critical to prevent the spread of HIV and other sexually transmitted infections. 133 The vast income differentials - Higate and Henry note that military observers in the DRC may have made 500-1000 times the local wages - set the context for this exploitative marketplace.134

\section{What do empirical and qualitative studies show about the prevalence of sexual abuse by} peacekeepers, including against displaced persons?

The UN's Conduct and Discipline Unit (CDU), established in 2007, is responsible for recording statistics on allegations of sexual exploitation and abuse by peacekeepers, with its Misconduct Tracking System established in 2008 (the CDU public website provides data from 2007 onwards). The first Secretary-General's annual Special Measures report was issued in 2005, with data for 2004. Drawn from these statistics, the following chart shows the UN's official tally of allegations recorded from 2004 to 2015, pertaining to UN peacekeeping personnel only:

\footnotetext{
128 Atwood et al., 'Transactional Sex among Youths in Post-Conflict Liberia,' p. 115.

129 UN Secretary-General, 'Investigation into Sexual Exploitation of Refugees by Aid Workers in West Africa', p. 7.

130 Nordås and Rustad, 'Sexual Exploitation and Abuse by Peacekeepers'.

131 Atwood et al., 'Transactional Sex among Youths in Post-Conflict Liberia'.

132 UNHCR and Save the Children UK, 'Sexual Violence and Exploitation - The Experience of Refugee Children in Guinea, Liberia and Sierra Leone,' p. 9.

133 Atwood et al., 'Transactional Sex among Youths in Post-Conflict Liberia'.

134 Higate and Henry, 'Engendering (In)security in Peace Support Operations', p. 485.
} 


\begin{tabular}{|r|r|}
\hline Year & $\begin{array}{r}\text { Number of reported allegations } \\
\text { by UN peacekeeping personnel }\end{array}$ \\
\hline 2004 & 105 \\
\hline 2005 & 340 \\
\hline 2006 & 357 \\
\hline 2007 & 127 \\
\hline 2008 & 83 \\
\hline 2009 & 112 \\
\hline 2010 & 85 \\
\hline 2011 & 75 \\
\hline 2012 & 60 \\
\hline 2013 & 66 \\
\hline 2014 & 52 \\
\hline 2015 & 69 \\
\hline &
\end{tabular}

The UN's statistics on allegations of sexual exploitation and abuse do not distinguish between victims who are ordinarily resident in a host country, internally displaced, or refugees. Part of the proposed research project's advocacy strategy will be to urge the UN to make available more granular, or detailed, statistics.

The under-reporting of rape, both in the general population and in conflict-affected areas, including amongst displaced populations

Some cases of abuse are reported and the fact that nothing happens can put other people off coming forward. 135

Around the world, whether in conflict or in peaceful situations, it is well-known that sexual violence is significantly under-reported. For instance, Statistics Canada finds that $90 \%$ of sexual assaults against women, other than where a spouse is accused, are not reported to the police. ${ }^{136}$ Save the Children finds that "official statistics on the scale of abuse appear disproportionately low in

135 Csáky, 'No One to Turn To', p. 14.

136 Maire Sinha, 'Measuring Violence against Women: Statistical Trends', Juristat (Statistics Canada, 25 February 2013), p. 96. http://www.statcan.gc.ca/pub/85-002-x/2013001/article/11766/11766-4eng.htm\#a1. 
comparison to the levels suggested by our fieldwork and other reports,"137 with "the chronic underreporting of abuse" a key finding. ${ }^{138}$ Studies consistently note that under-reporting as a problem. Jennings states that "local residents often do not report violations of the SEA policy, either because they benefit from them - sex work is a key component of most peacekeeping economies - or because they are not convinced that it will make a difference."139 Indeed, "negative experiences of legal and investigatory procedures"140 may dissuade victims and communities from reporting.

In the same vein, an expert team commissioned by the UN in 2013 to study four peacekeeping missions noted, amongst other reasons, that "multiple routes for reporting SEA" pose a challenge, particularly combined with "a strong emphasis on confidentiality to protect the accused."141 Missions identify a number of challenges: "a lack of knowledge of reporting mechanisms, difficulties reaching communities for outreach efforts and reluctance to report transactional sex."142 In 2015, the UN announced plans to roll out a model "community-based complaint reception mechanism" in peacekeeping missions to "encourage complainants to come forward." 143 However, it is unclear to what extent these mechanisms will be rolled out in hard-to-reach areas; whether communities will be trained appropriately; and whether this could result in cases not making it to the appropriate investigative and disciplinary authorities.

Overall, the reasons cited ${ }^{144}$ for not reporting sexual violence in peacekeeping contexts include factors common globally, as well as ones that are more specific to peacekeeping (and, to a related degree, aid contexts, which peacekeepers are sometimes dispatched to support):

- Stigmatisation, including associated with loss of virginity and fear of being considered less marriage-worthy, with associated negative economic implications

- Fear of ostracism

137 Csáky, 'No One to Turn To', p. 11.

138 Ibid, p. 12.

139 Kathleen Jennings, 'The UN's Shame: Sexual Exploitation and Abuse in UN Peacekeeping', E-International Relations, accessed 24 February 2016, http://www.e-ir.info/2015/10/21/the-uns-shame-sexualexploitation-and-abuse-in-un-peacekeeping/. 140 UNHCR and Save the Children UK, 'Sexual Violence and Exploitation - The Experience of Refugee Children in Guinea, Liberia and Sierra Leone,' p. 14.

141 Lutz, Awori, and Thapa, 'Expert Team's Final Report'.

142 United Nations Secretariat, 'Special Measures for Protection from Sexual Exploitation and Sexual Abuse: Report of the Secretary-General', 16 February 2016,

http://www.un.org/ga/search/view_doc.asp?symbol=a/70/729.

143 Ibid.

${ }^{144}$ Csáky, 'No One to Turn To'; UNHCR, 'Sexual Violence Against Refugees'; Lattu, 'To Complain or Not to Complain'; Martin, 'Must Boys Be Boys?' 
- Concern about lack of confidentiality in reporting mechanisms or by individuals to whom abuse is reported

- Fear of parental retaliation, for bringing shame

- Fear of retaliation or retribution by the individual accused

- Fear of losing financial, material or assistance due to retaliation or a withdrawal of peacekeepers

- Cultural perception that the victim is responsible, leading to fear of punishment

- Lack of awareness of rights, laws and policies

- Not knowing how to report, or to whom

- Inability of speaking the local or national language, particularly for displaced populations

- Fear the authorities would not take reports seriously, particularly for children without parental support

- Distrust of authorities

- Feelings of powerless, compounded by factors of race, class, ethnicity and nationality

- Lack of legal support

- Sense of hopelessness, in that reporting would not lead to action or justice, often based on observation or knowledge of experiences of others who have reported, and lack of awareness about outcomes of reports/investigations. 


\section{RESEARCH PROJECT PROPOSAL}

This section of the paper outlines the proposed research in greater detail, particularly from the perspective of how to bring the research proposal to fruition. After clarifying the proposed organizational structure of the project, I will set out the various considerations. It must be noted that this section is written with the understanding and expectation that the academic team conducting the research will flesh out and finesse the proposal in line with their expertise and experience, with legal counsel, and under the guidance of Ethics Board review from their respective academic institutions(s) and institutions in the host countries.

\section{Research project structure}

Research coordination: The research coordinator's role is to catalyze the research by: (i) identifying and approaching potential investigators and supervisory board members; (ii) identifying the funding and overseeing the budget, in conjunction with a colleague responsible for administrative support; (iii) identifying and hiring local "fixers" or experts to help the research team understand the local contexts, to establish and develop contacts, and plan the field visits; (iv) to provide support to the publication of results; and (v) to serve as the main liaison between the research team and the Code Blue campaign, particularly in the dissemination stage of the research, which will be coordinated with advocacy efforts. I anticipate that I would serve as the research coordinator for this project.

Research team: The research will be led be a principal investigator with a co-investigator. The research team will need to be able to work in English and in French, given the proposed study locations. The principal investigator will be responsible for (i) designing the study, in consultation with the supervisory board; (ii) seeking ethics review and approval; and (iii) leading the study in the field. She/he would then be responsible for (iv) reviewing and analysing the findings and writing up the results, with a view to writing at least one publication for a peer-reviewed journal. The team may draw on research assistants for support.

Supervisory board: In order to enhance the credibility of the research project, and have trusted experts guiding its design, implementation and dissemination, the research coordinator would assemble, in conjunction with the principal investigator, a 3-person supervisory board. The board will ideally comprise a diverse group of experts including (i) senior researchers with experience interviewing communities experiencing high levels of sexual violence, and/or with significant displaced populations; (ii) UN experts, possibly including former investigators with knowledge of 
the UN's reporting structures; and (iii) legal scholars or practitioners, particularly those with experience in peacekeeping contexts, with criminal law and/or with sexual violence. This is anticipated to be on a non-remunerated basis, although honorariums may be considered.

Host organizations and local researchers: Local researchers will conduct the focus group sessions and interviews, with oversight provided by the research team (in consultation with the supervisory board). Depending on the local context, local organizations working with displaced and vulnerable populations, and/or that are themselves identified by the UN as hosts for the "community-based complaint reception mechanisms," will be identified to "host" the focus groups. Researchers will be drawn from these local organizations or their contacts. The research team will be responsible for (i) training the local researchers, including on research ethics (e.g. maintaining confidentiality of the research participants and findings); (ii) discussing the proposed research questions with them and adapting the questions to the local context (based on the feedback received); and (iii) providing guidance and supervision of the process. Where sufficient capacity exists, the local researchers will support the review and analysis of the data, including writing up notes, coding the data, and conducting a preliminary analysis.

The Code Blue campaign and the research coordinator will play a lead role in identifying and establishing contacts, with the research team. To identify prospective partners, a one- or two-page summary of the research project will be prepared covering the purpose, objectives, methodology, timelines, location, research team and other partners, and dissemination strategy. Engaging local researchers has implications for privacy and confidentiality. Therefore, it will be important to ensure that all potential partners and researchers are carefully vetted and trained to reduce the risk of conflict of interest or potential harm to the study participants. Partners must be in a position to gain the trust of the participants and ensure confidentiality can be maintained, and be sensitive to the potential for trauma. They must also have sufficient knowledge of local laws, customs and context to advise the research team accordingly and ensure sound decisions throughout the research process. The research coordinator and team will seek best practices from other academic researchers that have conducted similar or relevant research in the proposed host countries and communities, as well as guidelines and codes of conduct developed by researchers (and organizations) pursuing similar or relevant research. The research coordinator will also consult contacts at other international NGOs (for instance, Amnesty International, Médecins Sans Frontières, and Human Rights Watch) operating in the host countries as part of vetting potential 
partners. The research team will also need to determine the appropriate remuneration (financial and/or in-kind) for the local partner organizations and researchers.

The individual researchers may be drawn from the local host organization, as appropriate, or recommended by it, with an emphasis on individuals who both know the local context and the situation of victims and vulnerable populations, and those seeking to develop and enhance their research capacity, to promote knowledge and skills development. For example, these may be $\mathrm{MA} / \mathrm{PhD}$ candidates or early-stage academics at local universities, or researchers at local civil society or research institutions, or other similar experts.

Role of Code Blue campaign: The Code Blue campaign will commission the research, and will likely provide some or all of the funding for it. Nonetheless, the research itself will be independent in order to preserve the academic freedom necessary for a credible, peer-reviewed journal publication of the results.

The Code Blue campaign will also provide in-kind resources for the research project. For example, it will provide the salary for the research coordinator. It will also provide advice and feedback on the selection of the team, design, methodology, implementation and dissemination, and will suggest contacts or outside experts and make introductions as necessary.

The Code Blue campaign's most significant role, apart from the research coordinator, will be its assistance in disseminating the research results, and in particular translating them into advocacy messages for the relevant audiences. For example, as discussed further in the dissemination and advocacy strategy section, it will issue a statement, write letters to appropriate UN and Member States officials and decision-makers, support the publication of video or infographics explaining the research, and convene meetings or workshops for the research team to discuss the findings.

\section{Key study considerations}

This is a preliminary review of the key considerations that will need to be closely examined by the research team in conjunction with the supervisory board, legal experts, and the ethics review board(s).

Consent: As discussed, given concerns around obtaining the consent of minors or their 
parents/guardians to participate in research, 145 the proposed study will not include minors in the focus groups or interviews.

Confidentiality: In peacekeeping contexts, as in any study or investigation on sexual violence, confidentiality is critical, as UN investigators have noted:

It was appreciated from the outset that witnesses might be reluctant to speak about sexual exploitation and other related matters out of fear of reprisal or stigmatization, or for cultural and social reasons. All witnesses were therefore assured of the protection of their identity and the confidentiality of the information provided. ${ }^{146}$

Given that local researchers will be conducting the focus groups and interviews, they will be given extensive training on confidentiality and research ethics more broadly. The research team will sit in on the focus groups, and possibly the interviews, to further provide guidance.

Requirements to report: One important consideration for the study is whether any mandatory reporting requirements will apply if child sex abuse is uncovered through the course of the research study. For instance, Canada's current Tri-Council Policy Statement: Ethical Conduct for Research Involving Humans stipulates that "in exceptional and compelling circumstances, researchers may be subject to obligations to report information to authorities to protect the health, life or safety of a participant or third party," whether through ethical codes or laws (including "those requiring the reporting of children in need of protection.") ${ }^{147}$ The policy notes that where there are "reasonably foreseeable disclosure requirements," researchers should advise participants through the consent process. ${ }^{148}$ Given these considerations, the proposed research project will not seek to involve victims directly, and especially not victims who are minors.

Nonetheless, there are two main risks that the study must anticipate: (i) that un-reported child sex abuse will be discovered through the focus groups and/or interviews; and (ii) that the research participants themselves have experienced sexual exploitation or abuse that they have not reported. These revelations may emerge owing to the research study's support, and/or the increased

\footnotetext{
145 Centre of Genomics and Policy (CGP) and Maternal Infant Child and Youth Research Network (MICYRN), 'Best Practices for Health Research Involving Children and Adolescents', 2012, http://www.genomicsandpolicy.org/en/best-practices-2012.

146 UN Secretary-General, 'Investigation into Sexual Exploitation of Refugees by Aid Workers in West Africa'.

147 Canadian Institutes of Health Research, Natural Sciences and Engineering Research Council of Canada, and Social Sciences and Humanities Research Council of Canada, 'Tri-Council Policy Statement: Ethical Conduct for Research Involving Humans', December 2014, p. 60, http://www.pre.ethics.gc.ca/pdf/eng/tcps22014/TCPS_2_FINAL_Web.pdf. 148 Ibid, p. 61.
} 
attention on this issue internationally and locally (which may make community leaders feel that reporting is less futile). On the latter, as they are adults, they hold the decision power about whether to report or not. On the former, as a general principle it remains the responsibility of those in positions of care and supervision of minors to report accordingly (local laws and practices will need to be studied further). These principles will be made clear at the start of the sessions, and any research participants who disclose abuse of children under their care will be provided with support on reporting options.

Prior to the field research component, these issues will be closely discussed with relevant ethics review boards (at the host institution of the research team, and in the host countries). A protocol with standard responses will be developed, in consultation with local researchers, who will also be trained on the subject. Social workers will be on hand to help guide research participants who are considering reporting (and to provide any trauma counselling necessary). Furthermore, research participants will be given a simple flyer with details for the mission's reporting hotline, as Kolbe's study in Haiti modelled. ${ }^{149}$ This is particularly important as some participants may choose to come forward to report abuses in their community after the completion of the formal study.

UN and non-UN peacekeepers: The scandal in CAR made clear that abuses by non-UN peacekeepers are not formally recorded by the UN's reporting systems, meaning that the "total" allegations reported in a given year reflect only those against UN peacekeepers. While this is not clear from the UN's public information, different reporting processes might be in place for abuses by non-UN peacekeepers: for example, it is not clear whether the proposed community-based complaint reception mechanisms are designed to receive reports of abuses by non-UN peacekeepers. This is an important avenue to explore to provide details about the processes, and to inform advocacy strategies.

\section{Methodological considerations ${ }^{150}$}

In light of the considerations above, which remain subject to further research and consideration by the research team and associated experts, the following design choices are envisaged.

Selection of research participants: The aim will be to recruit senior personnel of local civil society organizations and other community leaders. Ideally, participants will be involved in supporting victims and/or those vulnerable to victimization of peacekeeper sexual violence. This could include

149 Kolbe, "'It's Not a Gift When It Comes with Price”'.

150 This section draws in part on: Lattu, 'To Complain or Not to Complain'. 
community workers responsible for providing protection to girls, such as teachers, orphanage workers, and other child protection workers, as well as women's rights leaders and organizations. They play a key role in advocating for the rights of victims, including displaced populations, and in facilitating the reporting process. For instance, they support and accompany victims who wish to report to the UN or other authorities; partner with the UN to host community-based complaint reception mechanisms; and report abuse that they hear about directly to relevant authorities. As such, their views on the reporting process, new reforms and any associated outreach by the UN are critical.

Study type and design: For this qualitative study, the main method employed will be focus groups discussions. Academic and NGO research generally use focus groups to encourage participants to speak in general terms, not about their own personal experiences of abuse, but rather about general trends in their communities. The study's focus groups will be designed to provide rich qualitative data on the perceptions of local civil society organizations and community leaders. The main issues covered through the common questions will include: (i) the broad context of formally reporting sexual abuse by peacekeepers to people in positions of authority, whether within the UN or otherwise; (ii) factors associated with decisions for choosing to formally report or not; (iii) any barriers to, or challenges associated with, reporting; (iv) the particular experiences and/or vulnerability of displaced populations in their communities; and (v) and other concerns about the process or suggested solutions to address any concerns (for an illustrative, sample list of questions, see Appendix 1).

Consent forms will be drafted in simple language and local researchers will explain the concepts and forms verbally and visually, as some participants may be illiterate. For the pilot study in CAR, at least three focus group discussions will be organized, with no more than 6-10 participants per discussion. After the first focus group, the questions, responses and process will be assessed and any necessary changes made for the subsequent groups.

A limited number of focus group participants will be invited to participate in further, in-depth interviews with researchers to provide more detailed insights. Additional interview participants will be recruited first from the focus groups and then, as needed, through snowball sampling to identify appropriate and willing participants (inclusion criteria will be developed by the research 
team). Again drawing on Kolbe's ${ }^{151}$ techniques, interviews will be conducted at a location of the participants' choice, and will involve at least two researchers. Interviews will be semi-structured, with an initial set of questions that will be asked to all participants, and a list of prompts established to be employed as needed.

Research approach: The research team designing the study will need to determine the extent to which the research will be participatory, or at least consultative, with the research participants. This includes in terms of study design, development of questions, implementation, and analysis and dissemination of results. They should consult with the supervisory board about whether to determine this at the outset of the research design phase, or further along in the process in consultation with the selected local partner organization(s) (and local researchers). The extent that the approach can be participatory/consultative will likely depend on the capacity of local researchers to facilitate such collaboration.

Selection and involvement of participants, and research sites: Incentives will not be provided to participants, however reimbursement for any costs incurred will be provided. A small token of appreciation will be considered based on the local context, and with ethics review board approval for instance, providing a meal as part of the focus group discussions. The local partner organization and local researchers will play key roles in determining the appropriateness of all outreach in a manner that does not harm potential research participants or their communities.

The UN's 2002 study on sexual exploitation against refugees in West Africa noted that "the Investigation Team observed that some refugees were more willing to provide information outside the refugee camp environment, owing to fear of possible retaliation in the camps."152 Again, any decisions about the location of the focus groups and the interviews will be done with the local partner organizations, prioritizing the safety and best interests of participants.

Language and local context: All materials and questions will be translated into the appropriate local and official language(s), and adapted for the local context. The local partner organizations and researchers will be responsible for advising and preparing such materials; leading the focus groups and in-depth interviews in the participants' preferred language(s); and engaging translators as required.

\footnotetext{
${ }^{151}$ Kolbe, "'It"s Not a Gift When It Comes with Price"'.

152 UN Secretary-General, 'Investigation into Sexual Exploitation of Refugees by Aid Workers in West Africa', para 7.
} 
Selection of peacekeeping missions: As noted above, the pilot study will be in an IDP camp in CAR. Following the pilot, the methodology will be tweaked as needed and the teams will conduct research in at least two additional country contexts, likely South Sudan and DRC. The researchers would return to conduct the research in at least one additional IDP site in CAR, thus using the comparative research as a basis to inform additional research in CAR. This is useful to provide comparisons based on the different contexts:

- CAR: as noted, CAR has been at the centre of the latest peacekeeper sex abuse scandal since 2015. It would be interesting to explore why victims (or their guardians) and local organizations often did not appear to report abuses when they occurred prior to mid-2015 (the timing of the increase in reported allegations is correlated with the post-scandal phase and greater UN and international attention). Community members and civil society organizations - both local and international NGOs - there have played a key role in reporting allegations to the UN, including the original reports of child sex abuse by French peacekeepers involving young boys in 2014.

- South Sudan: it is a relatively new peacekeeping mission, similar in size and mandate to CAR and with a highly vulnerable IDP population, yet there has been only one allegation officially reported to date (in 2016).

- DRC: it is an older mission that still has a significant and vulnerable IDP population, and was at the centre of a massive peacekeeper sex abuse scandal in 2004-5.153 As such, it would have seen changes to whatever complaint reception mechanism was previously the model (the other two missions may have been set up with the newer community-based model from the outset). It has also witnessed the ebbs and flows of UN and international attention on the problem.

All three countries have high levels of sexual violence in the general population and committed by armed forces party to the conflicts, facilitating comparisons, particularly on perceptions about the UN's actions. A comparative study is useful as it allows researchers to draw out best (and worst) practices to inform recommendations. Moreover, it will enable more credible, systemic findings of possible barriers to, and challenges associated with, reporting sexual violence by peacekeepers, thereby facilitating subsequent advocacy.

153 Colum Lynch, 'U.N. Sexual Abuse Alleged in Congo (washingtonpost.com)', Washington Post, 16 December 2004. 
If resources are available, it may be fruitful to also conduct field research in Liberia, although the peacekeeping mission there is winding down, for the following reasons: (i) Liberia's recent laws on sexual violence are generally considered victim-friendly; (ii) several NGO and academic studies on sexual exploitation and abuse were conducted there over the past 15 years; and (iii) the country has historically high levels of displacement. While Haiti may also be considered, it does not have such a significant displaced population. However, it would be interesting to compare findings to Kolbe's 2015 study of transactional sex amongst adults, which was commissioned by the UN's OIOS. Furthermore, it might be worthwhile to compare countries with high levels of displacement (CAR, DRC and South Sudan) with one with less (Haiti). Security considerations, which will be assessed on a regular basis, may also necessitate the study be carried out in certain countries over others.

\section{Further considerations}

Risks and limitations, and mitigation strategies: The Code Blue campaign will enlist the services of pro bono lawyers in its network to fully research and consider the sensitive issues identified above. It will ask them to come up with a set of recommendations and guidance at the outset to inform the study design. These legal experts will also be retained to provide advice on any other legal considerations. A non-exhaustive selection of additional risks and mitigating strategies is outlined below.

A potential risk, previously alluded to, is that it will be challenging to identify suitable local organizations to partner with. To avoid the perception of a conflict of interest, the local partners and researchers should not be working directly or indirectly for the UN or its funds, programmes or agencies. In certain contexts this may be difficult, especially where the UN is closely involved in all aspects of IDP camp administration. In these cases, clear guidelines will be developed and an emphasis will be on finding partners that are not directly employed by the UN (for instance, contracted by an international NGO that is itself contracted by the UN or, ideally, other independent actors). Related, potential partners may be lacking capacity. Efforts will be made to put in place enhanced guidelines, provide training to increase the suitability of potential partners, and consider non-traditional civil society organizations. If the above mitigation factors are not sufficient, the research team would partner with international NGOs who could engage researchers directly.

It is not intended that the research project be kept a secret from the $\mathrm{UN}$, and it may be possible to work with the Organization to facilitate this independent research, particularly if pitched as 
assessing the UN's reforms relating to new complaint reception mechanisms. Consultations will be held with academics who have worked with the UN on sexual exploitation and abuse research. ${ }^{154}$

Although the proposed study will not be aiming to interview any victims about their experiences, but rather about community perceptions of sexual exploitation and abuse and the reporting context, there is nonetheless a risk of (re-)traumatization of participants, particularly amongst those who have experienced or witnessed abuse. As noted above, participants will be briefed about the reporting context and any participant who discloses abuse, whether in a focus group or in an interview, will be reminded of relevant considerations. Care will be taken to develop research questions that are sensitive to the local context, and are compassionate. Social workers and legal experts will be on hand should any study participants wish to consult them; and, as noted, participants will be provided with information on how to formally report. They will be supported by the host organization and their partners should they wish to report, and the Code Blue campaign will monitor follow-up accordingly.

The potential for differences of opinion, strategy and interpretation may arise with the Code Blue campaign, given its specific advocacy approach. Examples of best practices in civil society-academic partnerships for research will be further explored. Building on this, a Memorandum of Understanding will be signed between the research team and the Code Blue campaign to acknowledge the independence of the research project and the roles and responsibilities of all parties, along with appropriate dispute resolution mechanisms.

\section{Research implementation}

Timeline: The research coordinator will be responsible for establishing the anticipated timeline of the project, in consultation with the relevant parties. It is anticipated that the project will formally begin in September 2016, although the identification of the principal investigator, co-investigator and some supervisory board members may begin in advance in the pre-launch phase (MaySeptember 2016). The field visit portion will take place in spring 2017. A preliminary timeline is included as an appendix to this paper, with a more detailed timeline with project milestones to be developed with the principal investigator once engaged.

\footnotetext{
154 For instance, this could include Catherine Lutz and Thelma Awori, who co-authored the Expert Team's Final Report, and Athena Kolbe, whose recent fieldwork in Haiti was commissioned by OIOS.
} 
Partnerships and funding: The Code Blue campaign, having recently received a significant grant, may be in a position to fund the research directly, in part or in whole. The supervisory board, once constituted, will review the modalities of this funding from a conflict of interest perspective, with a view to establishing clear guidelines and protocols for ensuring the independence of the research, the roles and responsibilities of the various parties (including the research coordinator, who will be both employed directly the Code Blue campaign and, on a part-time basis, working on the research project), and the information and communication channels between the parties. On initial review, including to enhance the credibility of the study, it would seem important to seek alternate sources of funding for the research project to complement the Code Blue funding. This could include funding from academic institutions, research councils, or private public interest foundations. However, the project should begin with Code Blue start-up funding given the timeliness of the issue and the anticipated time needed to secure any outside funding.

Next steps: Following the completion of this research proposal and submission as an MRP, I will be responsible for catalyzing the research project in my anticipated role as research coordinator, including for the pre-launch phase. My first task will be to formally pitch the research project internally with the leadership of the Code Blue campaign, who have been consulted at the outset of the research proposal stage. Informed by internal consultations, I will conduct and/or develop:

- A mapping of potential stakeholders, including possible research team members, supervisory board members, local partner organizations in the pilot location, and funders.

- An executive summary of the research proposal as an aide to approaching potential collaborators for the research team and supervisory board.

- Further (and more formal) consultations with key academics and NGOs that have engaged in research on sexual exploitation and abuse, as well as academics in our network who have experience working with civil society partners on research, in consultation with the Code Blue co-Directors.

- A detailed research plan, indicating the outstanding research questions for both the prelaunch period and the start of the project, including those that will require legal expertise. If Code Blue engages a Summer Legal Fellow (a first year law student), she/he might support this process by conducting preliminary research to guide discussions with pro bono lawyers. 
- A revised proposal based on the mapping exercise, research and consultations, along with an updated timeline. It will include a one- to two-page summary and a slightly longer description of the project (approximately 5-8 pages total).

- A preliminary budget, in consultation with the AIDS-Free World Administrator.

The steps and materials outlined above represent a selection of the work to be carried out in the pre-launch phase, in order to have the project further fleshed out by its launch in September 2016. 


\section{DISSEMINATION AND ADVOCACY STRATEGY}

\section{Dissemination of academic findings}

There will be an expectation that the study's findings will be analyzed, written up, and submitted for publication in appropriate peer-reviewed publications, with recommendations developed as part of this process. The research team, in consultation with the supervisory board and the research coordinator, will be responsible for identifying other opportunities for academic engagement, namely workshops with other academics and key stakeholders, and presentations at academic conferences and in sessions organized by think tanks. In addition, the research team will be asked to develop a plan to share the findings with the research participants and the host communities. The Code Blue campaign may draw on the research findings, and bring along the research team, in direct engagement with senior UN officials and governments, both in New York/Geneva and in peacekeeping contexts. An emphasis will be placed on contextualizing the findings and discussing the implementation of recommendations.

Efforts will also be undertaken, including through the planned Sexual Violence and Peacekeeping Network that I am establishing with a colleague at the University of Birmingham (see Appendix 3), to use this research project to make linkages with academics, experts and graduate students who have conducted previous studies or are interested in generating new research. There are likely spin-off studies or opportunities to partner on this research project (for instance, sharing resources and contacts in host countries). Generating an updated body of scholarly research and literature, in line with a renewed interest in the topic owing to its spotlight in the international media, will help generate ideas and momentum for needed reforms.

\section{Advocacy strategy}

AIDS-Free World's Code Blue campaign will lead the development of an advocacy strategy to accompany the publication and the dissemination of the proposed study's results, and to determine how the results support its other campaign goals. It will play a key role in translating the scholarly findings for a mass audience; engaging the media; and pressing key decision-makers for policy reforms based on the results. The results will be made public on its website, accompanied by relevant fact sheets, infographics or other materials to publicize the findings. The campaign will also use the study's results to demand greater resources for supporting victims as part of UN peacekeeping budgets. 


\section{Follow-up studies and consultations}

It is clear that this initial study will provide a picture of one aspect of the impunity problem for sexual exploitation and abuse: barriers to, and challenges associated with, reporting. The findings of this preliminary research will ideally inform future consultations, led by the Code Blue campaign, on a better system for reporting abuses. This would be done as part of a package of reforms being proposed by the campaign to eliminate the UN's involvement in receiving, investigating and responding to allegations of sexual exploitation and abuse, which the campaign contends constitutes a conflict of interest. 155

155 Based on conversations with Paula Donovan, AIDS-Free World co-Director. 


\section{CONCLUSION}

This proposed research builds on earlier field studies, primarily in Liberia, that examine the experiences of displaced populations with regards to sexual exploitation and abuse by those sent to provide assistance and protection. It will offer specific insights into sexual violence by peacekeepers, from the point of view of community leaders and local organizations that support victims or vulnerable populations. As these abuses are arguably more difficult to prosecute than sexual violence by aid workers, given complex jurisdictional arrangements for discipline and criminal accountability, the research is particularly relevant. It will also update earlier research by focusing on newer peacekeeping missions, including those that have arguably stronger mandates to protect civilians and respond to rampant sexual violence within the host society and by armed parties to the conflicts.

The study will focus on one part of the problem, the reporting context, with a view to assessing current structures and recent UN reforms to roll out "community-based complaint reception mechanisms" where they do not currently exist. Only by improving reporting structures can abuses come to light, the full extent of the problem be known, and individual criminal responsibility be pursued where appropriate. Peacekeeper sexual violence threatens missions' very effectiveness, as we are seeing in CAR, and is undermining the UN's role as an essential global institution.

Responding to Save the Children's recommendations to combat under-reporting in 2008, a columnist noted this must be matched with measures to address accountability:

If the U.N. is unable to properly punish offenders, and local authorities in at-risk areas are unwilling to do so, abusers remain free. That impunity is an additional blow for children victimized not only by poverty and hardship, but in some cases by the very people sent to protect them. 156

This is the heart of the Code Blue campaign. Any efforts to understand the specific experiences of displaced populations, and to examine and strengthen the reporting context for sexual exploitation and abuse are necessary - but insufficient - steps to end the vicious cycle and general culture of impunity that currently exists for crimes of sexual violence by peacekeepers. This academic research, pitched in partnership with vigorous advocacy, will play an important role in exposing and combatting this most horrific and destructive unintended consequence of peacekeeping.

156 D. J. Siegelbaum, 'When Peacekeepers Prey on Children', Time, 27 May 2008, http://content.time.com/time/world/article/0,8599,1809761,00.html. 


\section{Appendices}

\section{Appendix 1 - Sample focus group and interview questions}

The following questions are for illustrative purposes only, and will be refined with the research team in consultation with the supervisory board and the ethics review process. The questions are based on focus group questions used in Csáky's study for Save the Children. ${ }^{157}$

- Do you know what constitutes prohibited conduct under the UN policy on sexual exploitation and abuse?

- Are there any groups or individuals that are particularly vulnerable to abuse in your community and/or IDP camp? If so, who are they?

- Is medical, psychosocial and legal support available in your area, or the areas your organization serves? (For IDPs): How does the support differ from your home area?

- Have you ever reported an abuse or supported someone who has reported an abuse, or have you heard of others in the community doing so?

- What follow-up was done after an abuse was reported?

- Where (or to whom) would you report an abuse?

- Is there a community-based complaint reception mechanism in your area? Do you know where it is and how to access it?

- What are your thoughts on the organization(s) or individuals responsible for hosting such a complaint reception mechanism? Do you trust them?

- How far do you have to travel to access the complaint reception mechanism? Is it available in all parts of your district?

$\circ$ Did the UN conduct outreach or training when the mechanism was being implemented?

- How different is the current model from previous structures?

- Was follow-up done after an abuse was reported through a community-based complaint reception mechanism? At what stage were local authorities, the UN, or other authorities involved?

- Do you also have access to reporting mechanisms at the UN base or with local authorities? If you needed to report, to which body would you turn?

- What challenges have you or someone in your community faced, if any, following a decision to report an abuse?

- What are the reasons why someone in your community might not report an abuse?

- Does increased international attention and/or UN presence encourage reporting?

- What other action might you take in response to a case of abuse?

- What can be done to encourage people in your community to report an abuse?

- What other action should be taken to improve the reporting process?

$\circ$ Are there any specific changes you would like to see to the community-based complaint reception mechanism?

157 Csáky, 'No One to Turn To,' p. 4. 


\section{Appendix 2 - Proposed timeline (Overview)}

Note: the project will be in pre-launch phase from May-August 2016.

\section{September - December 2016}

- Establish the research team and supervisory board, and develop Terms of Reference

- Develop the Memorandum of Understanding between the research project and the Code Blue campaign

- Determine the research project budget and appropriate funding model (note: if funding is sought solely through academic institutions or research councils, the project may be delayed while the funding proposal is being considered)

- Submit funding applications, as needed

- Identify potential local organization partners in the pilot site (this may involve a field visit by the research coordinator, possibly with the principal investigator)

- Write the research summary for potential partner organizations

- Develop the methodology

- Engage pro bono law firms to research the local context and laws in all proposed research sites to inform the research protocol

- Research best practices developed by relevant partner organizations/research institutions, including guidelines on reporting child sex abuse and appropriate ethics review boards for multi-country research

- Hire a research assistant (student) to conduct a comprehensive literature review, building on the MRP

\section{January 2017 - March 2017}

- Finalize the methodology, in consultation with relevant stakeholders

- Develop focus group questions

- Submit full research project proposal for ethics review board approval in both the home country academic institution and, as appropriate, with host country authorities

- Undertake logistical and administrative arrangements for site visit and field research

- Identify potential local organization partners in the additional sites (this may involve a field visit by the research coordinator, possibly with the principal investigator) 


\section{April-June 2017}

- Conduct pre-visit to pilot site to finalize partnerships and arrangements with local partners, and conduct training (roughly one week)

- Conduct field research in pilot site (roughly one week - note this may follow directly after the pre-visit)

- Write up notes, code and analyse data of pilot study

- Write up preliminary findings and results of pilot study

- Review methodology and plan next three field visits (another in pilot country, and two additional countries)

- Conduct pre-visit to additional sites to finalize partnerships and arrangements with local partners, and conduct training (roughly one week each)

- Conduct field research in additional sites (roughly one week each - this may follow directly after the pre-visit)

- Write up notes, code and analyse data of additional sites

- Write up preliminary findings and results of additional sites

\section{July-September 2017}

- Assess, analyse and write up overall study findings and results

- Share and validate research findings with local partner organizations, researchers and study participants

- Conduct workshop with Code Blue campaign to review findings and results, and plan advocacy strategy

\section{October-December 2017}

- Pitch academic article for publication

- Implement advocacy strategy and respond to emerging opportunities 


\section{Appendix 3 - About the proposed research coordinator}

I am the project coordinator of the Code Blue campaign. I joined AIDS-Free World, the nongovernmental advocacy organization leading the campaign, in June 2014, in the course of my Master's degree at Ryerson University. Prior to this, I served as research assistant to Stephen Lewis, a distinguished visiting professor at Ryerson and one of the two co-Directors of AIDS-Free World.

I am also on educational leave from Global Affairs Canada, where as a rotational foreign service officer I have held roles in Canada and abroad focusing on the intersection between development, human rights and foreign policy, and humanitarian and refugee affairs, with a focus on Africa. Through this service, I have experience conducting field-based research and participating in consultations in refugee and IDP camps.

I am also in the process of establishing the Sexual Violence and Peacekeeping Network with Dr. Rosa Freedman at the University of Birmingham Law School. This academic-civil society network is modelled on the Refugee Research Network, and we have applied for UK research council funding to launch the network in late 2016. The network will provide a unique opportunity to discuss the research proposed in the MRP with key experts, with a possible presentation at the network's second research workshop, on Causes and Consequences of Sexual Violence in Peacekeeping (planned for May 2017 in South Africa). It will also provide an invaluable network to identify potential members of the research team and supervisory board, and a network for local contexts in the three sites proposed for the field study.

Note: Much of the research contained in this MRP stems from my role with AIDS-Free World's Code Blue campaign. The MRP's analysis was often drawn directly from the insights of and my discussions with its co-Directors and my colleagues in the organization, and our partners around the world. For this, I am grateful. 


\section{BIBLIOGRAPHY}

AIDS-Free World. 'AIDS-Free World - Supplementary Written Evidence'. UK House of Lords, Select Committee on Sexual Violence in Conflict, 13 November 2015.

http://data.parliament.uk/writtenevidence/committeeevidence.svc/evidencedocument/sexualviolence-in-conflict-committee/sexual-violence-in-conflict/written/24616.html.

__- 'Another 41 Allegations of Peacekeeper Sexual Sex Abuse Undisclosed by the UN', 13 April 2016. http://www.codebluecampaign.com/press-releases/2016/4/13.

- — - 'Democracy Now Interview with Paula Donovan', 2 July 2015. http://www.codebluecampaign.com/latest-news/2015/7/16.

- - - 'Shocking New Reports of Peacekeeper Sexual Abuse in the Central African Republic', 30 March 2016. http://www.codebluecampaign.com/press-releases/2016/3/30.

- - - 'The UN Provided New Evidence Today That It Can't Solve Its Peacekeeper Sex Abuse Crisis from within', 29 January 2016. http://www.codebluecampaign.com/press-releases/2016/1/29-2.

_—_. 'Time for Dramatic Changes to End Peacekeeper Sexual Abuse', 26 January 2016. http://www.codebluecampaign.com/press-releases/2016/1/26.

———. 'UN Experts' Unseen Peacekeeping Report: Sexual Exploitation and Abuse', 16 March 2015. http://aidsfreeworld.org/Newsroom/Press-Releases/2015/Open-Letter-to-UN-Missions.aspx.

Atwood, Katharine A., Stephen B. Kennedy, Ernlee M. Barbu, Wede Nagbe, Wede Seekey, Prince Sirleaf, Oretha Perry, Roland B. Martin, and Fred Sosu. 'Transactional Sex among Youths in Post-Conflict Liberia'. Journal of Health, Population and Nutrition, 2011, 113-22.

Beber, Bernd, Michael J. Gilligan, Jenny Guardado, and Sabrina Karim. 'Peacekeeping, International Norms, and Transactional Sex in Monrovia, Liberia'. Working Paper, 2015. http://www.nyu.edu/projects/beber/files/Beber_Gilligan_Guardado_Karim_TS.pdf.

Burke, Róisín Sarah. Sexual Exploitation and Abuse by UN Military Contingents. Brill, 2014. http://booksandjournals.brillonline.com/content/books/9789004208483. 
Canadian Institutes of Health Research, Natural Sciences and Engineering Research Council of Canada, and Social Sciences and Humanities Research Council of Canada. 'Tri-Council Policy Statement: Ethical Conduct for Research Involving Humans', December 2014.

http://www.pre.ethics.gc.ca/pdf/eng/tcps2-2014/TCPS_2_FINAL_Web.pdf.

Centre of Genomics and Policy (CGP), and Maternal Infant Child and Youth Research Network (MICYRN).

'Best Practices for Health Research Involving Children and Adolescents', 2012.

http://www.genomicsandpolicy.org/en/best-practices-2012.

Charlesworth, Hilary. 'Feminist Methods in International Law'. The American Journal of International Law 93, no. 2 (1999): 379-94.

Csáky, Corinna. 'No One to Turn To. The under-Reporting of Child Sexual Exploitation and Abuse by Aid Workers and Peacekeepers.' Save the Children UK, 2008.

http://www.savethechildren.org.uk/sites/default/files/docs/No_One_to_Turn_To_1.pdf.

Defeis, Elizabeth F. 'UN Peacekeepers and Sexual Abuse and Exploitation: An End to Impunity'. Wash. U. Global Stud. L. Rev. 7 (2008): 185.

Deschamps, Marie, Hassan B. Jallow, and Yasmin Sooka. 'Taking Action on Sexual Exploitation and Abuse by Peacekeepers: Report of an Independent Review on Sexual Exploitation and Abuse by International Peacekeeping Forces in the Central African Republic', 17 December 2015. http://www.un.org/News/dh/infocus/centafricrepub/Independent-Review-Report.pdf.

Edith M. Lederer. 'US Group Says 98 Girls in CAfrican Republic Sexually Abused'. Associated Press, 30 March 2015. http://www.metronews.ca/news/world/2016/03/30/us-group-says-98-girls-incafrican-republic-sexually-abused.html.

Esslemont, Tom. 'EXCLUSIVE - UN Peacekeepers Face New Sex Allegations in Central African Republic'. Thomson Reuters Foundation, 11 November 2015. http://news.news.trust.org/item/20151111183717-batnu/.

Ferris, Elizabeth G. 'Abuse of Power: Sexual Exploitation of Refugee Women and Girls'. Signs 32, no. 3 (2007): 584-91. doi:10.1086/510338.

Ferstman, Carla. 'Criminalizing Sexual Exploitation and Abuse by Peacekeepers'. USIP Special Report, 2013. http://mercury.ethz.ch/serviceengine/Files/ISN/168975/ipublicationdocument_singledocument/ 
333ee55d-fe9a-4788-aa1f-bc624756e90e/en/SR335-

Criminalizing+Sexual+Exploitation+and+Abuse+by+Peacekeepers.pdf.

Freedman, Rosa. 'How Can We Hold the UN Accountable for Sexual Violence?' OUPblog, 7 February 2016. http://blog.oup.com/2016/02/un-accountable-sexual-violence/..

Government of Canada, Department of Justice. 'Frequently Asked Questions: Age of Consent to Sexual Activity', 11 February 2015. http://www.justice.gc.ca/eng/rp-pr/other-autre/clp/faq.html.

Government of Ontario, Ministry of Children and Youth Services. 'Reporting Child Abuse and Neglect: It's Your Duty', 2013.

http://www.children.gov.on.ca/htdocs/English/topics/childrensaid/reportingabuse/abuseandneg lect/abuseandneglect.aspx.

Groth, A. N., W. Burgess, and L. L. Holmstrom. 'Rape: Power, Anger, and Sexuality'. The American Journal of Psychiatry 134, no. 11 (November 1977): 1239-43. doi:10.1176/ajp.134.11.1239.

Guardado, Bernd Beber, Michael Gilligan, Jenny, and Sabrina Karim. 'U.N. Peacekeeping and Transactional Sex'. The Washington Post, 16 June 2015. https://www.washingtonpost.com/blogs/monkey-cage/wp/2015/06/16/u-n-peacekeeping-andtransactional-sex/.

Higate, Paul. 'Peacekeepers, Masculinities, and Sexual Exploitation'. Men and Masculinities 10, no. 1 (2007): 99-119.

Higate, Paul, and Marsha Henry. 'Engendering (In)security in Peace Support Operations'. Security Dialogue 35, no. 4 (1 December 2004): 481-98.

Human Rights Watch. 'Central African Republic: Rape by Peacekeepers', 4 February 2016. https://www.hrw.org/news/2016/02/04/central-african-republic-rape-peacekeepers.

———. 'Forgotten Children of War: Sierra Leonean Refugee Children in Guinea', 1 July 1999. https://www.hrw.org/report/1999/07/01/forgotten-children-war/sierra-leonean-refugeechildren-guinea.

Internal Displacement Monitoring Centre. 'Global Figures', n.d. http://www.internaldisplacement.org/global-figures. 
Jennings, Kathleen. 'Protecting Whom?: Approaches to Sexual Exploitation and Abuse in UN Peacekeeping Operations'. Fafo, 2008.

- - - 'Service, Sex, and Security: Gendered Peacekeeping Economies in Liberia and the Democratic Republic of the Congo'. Security Dialogue 45, no. 4 (1 August 2014): 313-30.

- - - 'The UN's Shame: Sexual Exploitation and Abuse in UN Peacekeeping'. E-International Relations. Accessed 24 February 2016. http://www.e-ir.info/2015/10/21/the-uns-shame-sexualexploitation-and-abuse-in-un-peacekeeping/.

- - - 'Unintended Consequences of Intimacy: Political Economies of Peacekeeping and Sex Tourism'. International Peacekeeping 17, no. 2 (April 2010): 229-43. doi:10.1080/13533311003625126.

Karim, Sabrina, and Kyle Beardsley. 'Explaining Sexual Exploitation and Abuse in Peacekeeping Missions: The Role of Female Peacekeepers and Gender Equality in Contributing Countries'. Journal of Peace Research 53, no. 1 (January 2016): 100-115. doi:10.1177/0022343315615506.

Kent, Vanessa. 'Protecting Civilians from UN Peacekeepers and Humanitarian Workers: Sexual Exploitation and Abuse'. In Unintended Consequences of Peacekeeping Operations, edited by Chiyuki Aoi, Cedric de Coning, and Ramesh Thakur, 44-66. United Nations University Press, 2007.

Kolbe, Athena Rebecca. “It's Not a Gift When It Comes with Price”: A Qualitative Study of Transactional Sex between UN Peacekeepers and Haitian Citizens'. Stability: International Journal of Security and Development 4, no. 1 (2015). http://www.stabilityjournal.org/article/view/sta.gf/.

Lattu, Kirsti. 'To Complain or Not to Complain: Still the Question'. HAP - Humanitarian Accountability Partnership International, June 2008.

http://www.keepingchildrensafe.org.uk/sites/default/files/to_complain_or_not_to_complain_benef iciaries_perceptions_of.pdf.

Laville, Sandra. 'UN Aid Worker Suspended for Leaking Report on Child Abuse by French Troops'. The Guardian, 29 April 2015, sec. World news. http://www.theguardian.com/world/2015/apr/29/unaid-worker-suspended-leaking-report-child-abuse-french-troops-car.

'Legal and Ethical Considerations in Research With Sexually Active Adolescents: The Requirement to Report Statutory Rape'. Accessed 27 March 2016. https://www.guttmacher.org/pubs/journals/3425902.html. 
Logie, Carmen H., and CarolAnn Daniel. “My Body Is Mine”: Qualitatively Exploring Agency among Internally Displaced Women Participants in a Small-Group Intervention in Leogane, Haiti'. Global Public Health 11, no. 1-2 (7 February 2016): 122-34.

Lutz, Catherine, Thelma Awori, and Thapa, General Paban J. 'Final Report: Expert Mission to Evaluate Risks to SEA Prevention Efforts in MINUSTAH, UNMIL, MONUSCO and UNMISS', 3 November 2013. http://aidsfreeworld.org/Newsroom/Press-

Releases/2015/ /media/Files/Peacekeeping/2013\%20Expert\%20Team\%20Report\%20FINAL.pd f.

Lutz, Catherine, Matthew C. Gutmann, and Keith Brown. 'Conduct and Discipline in UN Peacekeeping Operations: Culture, Political Economy and Gender', 19 October 2009. http://papers.ssrn.com/sol3/papers.cfm?abstract_id=2323758.

Lynch, Colum. 'U.N. Sexual Abuse Alleged in Congo (washingtonpost.com)'. Washington Post, 16 December 2004.

Machel, Graça. 'Impact of Armed Conflict on Children'. United Nations, 1996. http://www.unicef.org/graca/a51-306_en.pdf.

Martin, Sarah. 'Must Boys Be Boys?: Ending Sexual Exploitation and Abuse in UN Peacekeeping Missions'. Refugees International, October 2005.

http://www.humanrightsvoices.org/assets/attachments/articles/1890_must_boys_be_boys.pdf.

McGill, Jena. 'Survival Sex in Peacekeeping Economies'. Journal of International Peacekeeping 18, no. 1-2 (2014): 1-44.

Moscoe, Adam. 'Sexual Exploitation and Abuse in United Nations Peace Operations: Towards EvidenceBased Prevention and Response', 11 December 2015. http://www.ruor.uottawa.ca/handle/10393/33449.

Ndulo, Muna. 'Sexual Abuse and Sexual Exploitation in Conflict Situations as a Security Risk'. EInternational Relations, 22 June 2015. http://www.e-ir.info/2015/06/22/sexual-abuse-and-sexualexploitation-in-conflict-situations-as-a-security-risk/.

Neudorfer, Kelly. 'Reducing Sexual Exploitation and Abuse: Does Deterrence Work to Prevent SEAs in UN Peacekeeping Missions?' International Peacekeeping 21, no. 5 (2014): 623-41. 
- - - Sexual Exploitation and Abuse in UN Peacekeeping: An Analysis of Risk and Prevention Factors. Lexington Books, 2014.

Nordås, Ragnhild, and Siri C. A. Rustad. 'Sexual Exploitation and Abuse by Peacekeepers: Understanding Variation'. International Interactions 39, no. 4 (September 2013): 511-34.

Onanga-Anyanga, Parfait. 'Opinion: How the U.N. Is Countering Child Sex Abuse by Its Troops'. Newsweek, 30 March 2016. http://www.newsweek.com/how-un-countering-child-sex-abuse-troops-442315.

Otto, Dianne. 'Making Sense of Zero Tolerance Policies in Peacekeeping Sexual Economies'. Sexuality and the Law, 2007, 259-82.

Save the Children UK. 'From Camp to Community: Liberia Study on Exploitation of Children'. Discussion Paper, 2006. https://www.essex.ac.uk/armedcon/story_id/000381.pdf.

Sieff, Kevin. 'The Growing U.N. Scandal over Sex Abuse and "peacekeeper Babies"'. Washington Post, 27 February 2016. http://www.washingtonpost.com/sf/world/2016/02/27/peacekeepers/.

Siegelbaum, D. J. 'When Peacekeepers Prey on Children'. Time, 27 May 2008. http://content.time.com/time/world/article/0,8599,1809761,00.html.

Simic, Olivera. Regulation of Sexual Conduct in UN Peacekeeping Operations. Berlin, Heidelberg: Springer Berlin Heidelberg, 2012. http://link.springer.com/10.1007/978-3-642-28484-7.

Simm, Gabrielle. Sex in Peace Operations. West Nyack: Cambridge University Press, 2013.

Sinha, Maire. 'Measuring Violence against Women: Statistical Trends'. Juristat. Statistics Canada, 25 February 2013. http://www.statcan.gc.ca/pub/85-002-x/2013001/article/11766/11766-4eng.htm\#a1.

UNHCR. '2015 UNHCR Country Operations Profile - Central African Republic', December 2015. http://www.unhcr.org/pages/49e45c156.html.

- - Conclusion on Protection from Sexual Abuse and Exploitation, 2003. http://www.unhcr.org/3f93b2c44.html.

—_—. 'Internally Displaced People'. Accessed 27 March 2016. http://www.unhcr.org/pages/49c3646c146.html. 
——_. 'Refugee Children: Guidelines on Protection and Care', 1994.

http://www.unicef.org/violencestudy/pdf/refugee_children_guidelines_on_protection_and_care.pd f.

——_. 'Sexual Violence Against Refugees: Guidelines on Prevention and Response', 1995. http://www.unhcr.org/3b9cc26c4.html.

UNHCR, and Save the Children UK. 'Sexual Violence and Exploitation - The Experience of Refugee Children in Guinea, Liberia and Sierra Leone', February 2002. http://www.savethechildren.org.uk/sites/default/files/docs/sexual_violence_and_exploitation_1.p df.

United Nations, Conduct and Discipline Unit. 'Overview of Statistics'. Accessed 28 March 2016. https://cdu.unlb.org/Statistics/OverviewofStatistics.aspx.

_- - 'Statistics: Allegations by Category of Personnel Per Year (Sexual Exploitation and Abuse)'. Statistics: Allegations by Category of Personnel Per Year (Sexual Exploitation and Abuse), n.d. https://cdu.unlb.org/Statistics/AllegationsbyCategoryofPersonnelSexualExploitationandAbuse/All egationsbyCategoryofPersonnelPerYearSexualExploitationandAbuse.aspx.

- — - 'Statistics: Sexual Exploitation and Abuse Allegations Per Year Involving Minors'. Statistics: Sexual Exploitation and Abuse Allegations Per Year Involving Minors, n.d.

https://cdu.unlb.org/Statistics/SexualExploitationandAbuseAllegationsInvolvingMinors/SexualEx ploitationandAbuseAllegationsPerYearInvolvingMinors.aspx.

- - - 'Status of Allegations, Investigations and Actions (Sexual Exploitation and Abuse)', Accessed 24 April 2016.

https://cdu.unlb.org/Statistics/DetailedOverviewofAllegationsfrom2015onward/StatusofAllegatio nsInvestigationsandActionsSexualExploitationandAbuse.aspx

United Nations, Department of Peacekeeping Operations. 'Current Peacekeeping Operations'. Accessed 27 March 2016. http://www.un.org/en/peacekeeping/operations/current.shtml.

- - - 'Peacekeeping Fact Sheet', 29 February 2016. http://www.un.org/en/peacekeeping/documents/bnote0216.pdf. 
——_. 'Women in Peacekeeping'. Accessed 27 March 2016.

http://www.un.org/en/peacekeeping/issues/women/womeninpk.shtml.

United Nations, Office for the High Commissioner for Human Rights. 'South Sudan: UN Report Contains “Searing” Account of Killings, Rapes and Destruction', 11 March 2016.

http://www.ohchr.org/EN/NewsEvents/Pages/DisplayNews.aspx?NewsID=17207\&LangID=E.

United Nations, Office of the Special Representative of the Secretary-General for Children and Armed

Conflict. 'The Rights and Guarantees of Internally Displaced Children in Armed Conflict'. Working Paper No 2, September 2010.

https://childrenandarmedconflict.un.org/publications/WorkingPaper-2-Rights-GuaranteesIDPChildren.pdf.

United Nations, News Service. 'UN News - UN Sexual Misconduct Investigation in DR Congo Finds Violations and Cases of Abuse'. UN News Service Section, 4 April 2016.

http://www.un.org/apps/news/story.asp?NewsID=53609\#.Vx5dHDYrLx4.

United Nations Secretariat. Secretary-General's Bulletin: Special Measures for Protection from Sexual Exploitation and Sexual Abuse, 2003.

http://www.un.org/ga/search/view_doc.asp?symbol=ST/SGB/2003/13.

- - - 'Special Measures for Protection from Sexual Exploitation and Sexual Abuse: Report of the Secretary-General', 13 February 2015.

http://www.un.org/ga/search/view_doc.asp?symbol=a/69/779.

- - - 'Special Measures for Protection from Sexual Exploitation and Sexual Abuse: Report of the Secretary-General', 16 February 2016.

http://www.un.org/ga/search/view_doc.asp?symbol=a/70/729.

United Nations Secretary-General. 'Framework of Actions for the Follow-up to the Programme of Action of the International Conference on Population and Development Beyond 2014: Report of the Secretary-General'. United Nations, 12 February 2014.

https://www.unfpa.org/sites/default/files/pub-pdf/ICPD_beyond2014_EN.pdf.

- - - 'Investigation into Sexual Exploitation of Refugees by Aid Workers in West Africa: Note by the Secretary-General', 11 October 2002. http://www.refworld.org/docid/3deb32dd4.html. 
